\title{
Renda, Relações Sociais e Felicidade no Brasil
}

\author{
Carlos Antonio Costa Ribeiro
}

Universidade do Estado do Rio de Janeiro (UERJ), Rio de Janeiro, RJ, Brasil. E-mail: carloscr@iesp.uerj.br.

\section{INTRODUÇÃO}

T á uma interpretação corrente e bastante popular de que o Brasil é 1 o país do futebol e do carnaval, expressões da alegria, descontração e felicidade que caracterizam seu povo. Apesar das diversas dificuldades econômicas e sociais que marcam a história do país, a população teria algo que a diferenciaria de outras: a simpatia e a alegria. Características que facilitariam a sociabilidade e que estariam sempre presentes, a despeito das violências e injustiças. O povo brasileiro ser essencialmente feliz é uma ideologia comum. Outra ideia comum é a que estabelece uma relação positiva entre o aumento da renda dos indivíduos e o aumento da felicidade ou, de forma mais geral, entre condições materiais e sentimentos. Crescimento econômico seria equivalente a aumento da satisfação com a vida. Assim, a melhora recente das condições de vida no país teria contribuído para aumentar ainda mais o grau de alegria dos brasileiros ${ }^{1}$.

Estudos anteriores sobre felicidade no Brasil mostram uma correlação fraca, mas positiva, entre renda e bem-estar percebido (Cavalcanti, Guimarães e Nogueira, 2009; Corbi e Menezes-Filho, 2006; Islam, Wills-Herrera e Hamilton, 2009; Luz et al., 2011; Mendes-da-Silva et al., 2013). Estes estudos, no entanto, não fazem análises incluindo os assim chamados "bens relacionais", que dependem essencialmente de relações interpessoais como amizade, família, comunidade etc. De acordo

DADOS - Revista de Ciências Sociais, Rio de Janeiro, vol. 58, n- 1, 2015, pp. 37 a 78. 
com a literatura, estas relações sociais estão fortemente correlacionadas à felicidade (Ramírez, 2012). O objetivo deste artigo é analisar não apenas o efeito da renda, mas sobretudo os de alguns tipos de percepção e relação social associados à felicidade.

Enquanto os estudos anteriores sobre felicidade no Brasil enfatizaram a relação entre renda e bem-estar subjetivo, mostrando que aumento da renda realmente corresponde a aumento do bem-estar subjetivo, argumento que fatores relacionados à sociabilidade dos indivíduos também são essenciais para entendermos o grau de felicidade da população brasileira. Assim, minhas análises mostram que, além das condições materiais (renda, educação e área de residência), fatores ligados às relações pessoais (casamento, amizade ou capital social e religiosidade) e a percepções sobre renda e saúde são fundamentais para explicar a variação no grau de felicidade da população brasileira. Os fatores ligados à sociabilidade e à percepção dos indivíduos se somam aos efeitos da renda para explicar a variação no grau de felicidade da população. São todos fatores que foram classicamente estudados pela sociologia, que sempre enfatizou a importância da integração dos indivíduos nas comunidades como fundamental para explicar a coesão e o sentimento de pertencimento dos indivíduos. Assim, a satisfação com a vida dependeria não apenas das condições materiais, mas também do grau e sentimento de pertencimento que os indivíduos têm em relação a suas comunidades.

Para desenvolver essa discussão, no entanto, é fundamental saber o que é a felicidade. Essa é provavelmente uma das perguntas mais antigas que existem. Uma grande parte dos escritos filosóficos se dedicou a definir o que seria uma vida boa e feliz ${ }^{2}$. Vários psicólogos também vêm se dedicando ao tema. É comum a afirmação de que a felicidade seria o fim último da vida, mas muitos argumentam que não há um fim último e que a felicidade seria encontrada nos meios que usamos para alcançar diversos objetivos. Uma vida satisfatória no amor, no trabalho, na amizade e em tantos outros aspectos seria de fato o que traz a felicidade. Apesar destes enormes esforços intelectuais não há consenso sobre o que seja a felicidade. Uma alternativa analítica é pedir para cada indivíduo dizer se é ou não feliz. Assim seria possível compilar essa informação para definir o grau de felicidade, ou bem-estar percebido, de populações inteiras.

De fato, é exatamente por ser tão difícil definir a felicidade que um grupo de sociólogos, economistas e psicólogos acredita que a melhor 
maneira de estudar o tema é perguntar às pessoas que compõem a população o quanto são felizes (Easterlin, 2002; Frey e Stutzer, 2002; Inglehart, 1990, 1997; Kahneman, Diener e Schwarz, 1999; Oswald, 1997; Veenhoven, 1993). É justamente essa abordagem que adoto neste artigo, ou seja, em vez de fazer um balanço de como diferentes intelectuais definiram o que torna as pessoas e, em particular, os brasileiros felizes ou infelizes, parto da avaliação que a própria população faz. Assim, analiso a percepção dos brasileiros sobre seu grau de felicidade ou, melhor dizendo, de "satisfação com a vida que levam".

Partindo desse ponto de vista pragmático, procuro definir se o grau de "satisfação com a vida" declarado por 8.951 indivíduos entrevistados em uma pesquisa amostral representativa da população brasileira se relaciona com suas condições materiais de vida, por um lado, e com seus graus de sociabilidade (ou intensidade de relações sociais e afetivas) e suas percepções sobre saúde e renda, por outro. Uma das perguntas que mais aguça a curiosidade das pessoas é saber se o dinheiro compra a felicidade. Será que as pessoas com renda mais alta tendem a estar mais satisfeitas com a vida que levam? Como demonstro ao longo do artigo, a renda é importante, mas minhas análises mostram que há outros fatores relacionados às relações de amizade e afetivas (casamento), às percepções sobre a própria saúde e sobre a renda e a religiosidade que também são altamente relevantes para entendermos o grau de felicidade dos brasileiros. Condições materiais e relações sociais são, em graus diferentes, fundamentais para explicar a variação na felicidade.

Assim sendo, o principal objetivo deste artigo é estimar um modelo multivariado incluindo não apenas aspectos econômicos (renda) como também aspectos contextuais (capital social, estado civil, religiosidade e percepções) e demográficos (idade e gênero) correlacionados à felicidade. Um problema central na estimação deste modelo é o da endogeneidade, ou seja, não é totalmente evidente qual a ordem das correlações. Por exemplo, será queé o casamento que aumenta a felicidade, ou é a felicidade que leva ao casamento? Este tipo de problema não pode ser resolvido metodologicamente, mas apenas recorrendo-se à teoria e à literatura já existentes sobre o tema. Portanto, argumento em favor do uso de cada variável independente ou explicativa recorrendo à literatura empírica e teórica sobre felicidade. Não há outra maneira de proceder. Antes de desenvolver o modelo multivariado proposto, que 
é a principal novidade deste artigo, apresento dados comparando o Brasil com diversas outras nações.

Também apresento no artigo a rica literatura sobre a mensuração do "bem-estar subjetivo", "satisfação com a vida", ou "felicidade" (ao longo do artigo usarei principalmente o último termo). Embora a mensuração de algo tão subjetivo possa ser criticada por alguns cientistas sociais que ainda se apavoram ao ver números e estatísticas, diversos pesquisadores argumentam que este tipo de informação é relativamente confiável (Kahneman e Krueger, 2006). Por que não medir algo tão importante como a felicidade? Temos tantas informações sobre aspectos objetivos da nação (renda, educação etc.), mas poucas sobre o sentimento e as percepções da população (felicidade, concepções de justiça etc.), ou seja, sobre os aspectos subjetivos da estratificação social. Tendo em vista que a felicidade pode ser considerada um dos fins últimos de uma vida boa e, portanto, um objetivo que o país deveria considerar como fundamental para sua população, parece ser de suma importância desenvolver estatísticas sociais nesta área. Este artigo pretende contribuir nessa direção.

Na próxima seção exponho brevemente algumas questões centrais da área de pesquisas sobre felicidade desenvolvidas atualmente por diversos cientistas sociais. Em seguida apresento dados que comparam o Brasil com outros países e os dados e métodos que uso para estimar um modelo multivariado para explicar a variação na média de felicidade da população brasileira. Nas seções subsequentes analiso os dados brasileiros com o objetivo de definir níveis de desigualdade da felicidade, ou seja, estudar os principais fatores correlacionados à felicidade da população. No final apresento, como de costume, as principais conclusões que podem ser retiradas das análises e reflexões desenvolvidas ao longo do trabalho.

\section{CONDIÇÕES MATERIAIS, RELAÇÕES SOCIAIS E FELICIDADE}

A principal motivação na literatura acadêmica sobre felicidade vem da ideia de que haveria uma correlação positiva entre condições materiais e satisfação com a vida. Essa preocupação pode ser resumida na pergunta: "Dinheiro compra felicidade?" (Does money buy hapiness?). Em 1973, o economista Richard Easterlin publicou um artigo com este título no qual apresentou um questionamento que passou a ser conhecido como o "Paradoxo de Easterlin". Ele dizia o seguinte: "Em todas as so- 
ciedades, mais dinheiro para o indivíduo tipicamente significa mais felicidade para o indivíduo. No entanto, aumentar a renda de todos não aumenta a felicidade de todos" (Easterlin, 1973:4; tradução livre).

De acordo com Easterlin (1973; Easterlin et al., 2010), a solução para esse paradoxo está na natureza relativa dos julgamentos de bem-estar pessoal. Os indivíduos fazem julgamentos sobre seu bem-estar baseados em normas sociais e comparações com outros indivíduos, mas não somente baseados em sua condição material objetiva. Os julgamentos seriam relativos à condição das outras pessoas. Portanto, investigando a relação entre as distribuições de renda e de felicidade em um momento específico do tempo (sincronicamente) constata-se que os mais ricos são mais felizes. Mas comparando dois momentos no tempo, verifica-se que o aumento da renda de todos não leva a um aumento da felicidade de todos. As pessoas definem sua felicidade não apenas em relação a suas condições materiais, mas sobretudo em relação à situação das outras pessoas a sua volta. O sociólogo W. G. Runciman (1966), por sua vez, ampliou essa noção e desenvolveu o conceito de "privação relativa", segundo o qual o sentimento de privação das pessoas depende mais do lugar que ocupam em uma comunidade do que das condições materiais específicas de que gozam.

A hipótese de Easterlin foi criticada por alguns autores (Hagerty e Veenhoven, 2003; Stevenson e Wolfers, 2008) que, usando dados sobre diversos países, sugerem que o crescimento econômico e o aumento da renda levam efetivamente ao aumento da felicidade da população, ou seja, haveria uma correlação positiva entre renda e felicidade. Em outras palavras, a mesma correlação positiva entre renda e felicidade que é encontrada ao nível individual em amostras transversais também estaria presente para sociedades que apresentam crescimento econômico ao longo dos anos. O próprio Easterlin (1973; Easterlin et al., 2010) apresentou análises defendendo sua hipótese inicial de 1973. Embora o debate ainda não esteja encerrado, há um enorme conjunto de pesquisas sobre o tema - que é apresentado em suas diversas facetas em um livro sobre bem-estar (well-being) organizado por um grupo de psicólogos (Kahneman, Diener e Schwarz, 1999).

De fato, a literatura mostra que diversos aspectos da vida, tais como relações sociais (amizade e casamento, por exemplo) e percepção sobre a própria condição de saúde, estão fortemente correlacionados à felicidade. Neste sentido, a renda não seria o principal fator explicando a fe-

DADOS - Revista de Ciências Sociais, Rio de Janeiro, vol. 58, nº 1, 2015 
licidade. Depois que os indivíduos deixam níveis de renda que implicam grande privação material, há diversos outros fatores que contribuiriam muito mais do que a renda para o aumento da felicidade (Frey e Stutzer, 2002). Tendo em vista que o Brasil está finalmente avançando no sentido de terminar com a miséria (entre 1981 e 2009 o percentual de pobres no Brasil caiu de $33,3 \%$ para $16,3 \%)^{3}$ passa a ser ainda mais importante conhecer os fatores que contribuem para que sua população se sinta ou não satisfeita com a vida que leva. A literatura sobre felicidade no Brasil, desenvolvida sobretudo por economistas (Cavalcanti, Guimarães e Nogueira, 2009; Corbi e Menezes-Filho, 2006; Islam, Wills-Herrera e Hamilton, 2009; Luz et al., 2011; Mendesda-Silva et al., 2013), enfatizou principalmente o efeito das condições materiais na felicidade. Minha proposta neste artigo, como argumentei na introdução, é verificar em que medida fatores como relações sociais, afetivas e percepções (sobre saúde e renda) contribuem para explicar a variação na felicidade da população brasileira ${ }^{4}$.

Para avançar neste sentido é fundamental desenvolver formas acuradas de mensurar a felicidade. Neste trabalho, assim como em vários outros que usam pesquisas amostrais da população (ver diversos trabalhos citados ao longo deste artigo), adoto uma mensuração global e subjetiva da felicidade que é obtida a partir de duas perguntas (ver mais adiante a seção intitulada O Brasil no Contexto Internacional) sobre o sentimento das pessoas em relação à sua vida de um modo geral. Embora aparentemente limitada, essa medida global vem se mostrando bastante útil para determinar esse sentimento. Uma outra forma de mensurar a felicidade é chamada de mensuração objetiva e é comum em estudos de laboratório em que a satisfação das pessoas é medida a partir de instrumentos observando estados de prazer e desprazer. Este segundo tipo de mensuração é chamado de objetivo simplesmente porque não depende das respostas das pessoas sobre o que estão sentindo. Entre estes dois opostos há estudos seguindo um método denominado experience sampling measures (Kahneman e Krueger, 2006). Este tipo de pesquisa acompanha os indivíduos em vários momentos do dia, realizando perguntas sobre como estão se sentindo. Ao fim, é possível ver em que momentos os indivíduos tendem a estar mais satisfeitos, o que permite ajustar as medidas para várias mudanças de humor e bem-estar que ocorrem na vida cotidiana.

Estas três formas de mensurar o bem-estar ou a felicidade, como insiste a literatura, seriam válidas, mas, para avaliar o grau de felicidade da 
população, a primeira abordagem é a mais adotada simplesmente pelo fato de ser a única passível de ser executada em estudos globais sobre populações muito grandes. Alguns trabalhos mostram que há correlação bastante significativa entre as três formas de mensuração (idem).

Estudar e mensurar a felicidade é importante por diversos motivos. O principal objetivo, que inspira este artigo, é o de simplesmente saber o quão satisfeitas as pessoas estão com a vida que levam. Será que ricos são mais felizes do que pobres? Jovens mais felizes do que velhos? A mensuração global da felicidade permite fazer estas comparações e verificar os principais fatores relacionados à distribuição diferencial do grau de felicidade das populações. Conhecer esses fatores é importante porque permite entender como a situação pode ser melhorada. De acordo com a literatura, há cinco aspectos que afetam a felicidade: (1) personalidade (por exemplo, autoestima, otimismo, extroversão etc.); (2) características sociodemográficas (idade e sexo); (3) fatores econômicos (renda, desemprego, educação, inflação etc.); (4) fatores contextuais e situacionais (condições de trabalho, relações interpessoais de amizade e com parentes, casamento, percepções sobre condições materiais e de saúde); e (5) fatores institucionais (tais como participação política).

Neste artigo estimo um modelo estatístico multivariado que leva em conta os aspectos demográficos (2), econômicos (3) e contextuais (4). Os outros dois não são incluídos porque não tenho informações para eles na pesquisa utiliza. Assim, as análises desenvolvidas permitem descrever os principais fatores correlacionados à felicidade da população brasileira. A principal novidade de minhas análises é a inclusão dos fatores contextuais para explicar a variação na felicidade entre os brasileiros, uma vez que algumas análises sobre o efeito da renda na felicidade já foram desenvolvidas (Neri, 2012; Cavalcanti, Guimarães e Nogueira, 2009; Corbi e Menezes-Filho, 2006; Islam, Wills-Herrera e Hamilton, 2009; Luz et al., 2011; Mendes-da-Silva et al., 2013).

De fato, a ideia de que os cinco fatores aqui apresentados são importantes para descrever o grau de felicidade das populações é resultado de pesquisas interdisciplinares envolvendo tradições de estudo na sociologia, na psicologia e na economia. Foram sociólogos com pendor para análises quantitativas usando amostragens de populações inteiras que começaram, há muitos anos, a desenvolver métodos para avaliar aspectos subjetivos da população tais como ideologias, sentimentos e ati-

DADOS - Revista de Ciências Sociais, Rio de Janeiro, vol. 58, nº 1, 2015 
tudes. Em outras palavras, a preocupação sociológica com o pertencimento dos indivíduos a comunidades a partir de seus valores e percepções criou uma tradição de coleta de informações sobre aspectos subjetivos das sociedades (Inglehart et al., 2004). Paralelamente, psicólogos sociais de diversas correntes começaram a desenvolver pesquisas experimentais, com grupos menores e mais restritos, com o objetivo de mensurar o bem-estar, a felicidade e outros aspectos da vida sentimental das pessoas. Estes estudos levaram a ideias importantes sobre as influências contextuais nas decisões dos indivíduos, vieses de cognição e limitações na habilidade dos indivíduos em prever o futuro (ver, por exemplo, "Prospect Theory", de Kahneman e Tversky, 1979). Valendo-se da tradição sociológica de mensurar aspectos subjetivos e de percepção dos indivíduos na população e da crítica da psicologia experimental a uma visão do indivíduo como puramente "racional", alguns economistas começaram a se interessar pelo estudo da felicidade.

De fato, nas ciências econômicas, o estudo da felicidade passou a ganhar importância na medida em que a mensuração deste aspecto subjetivo faz com que esta disciplina se volte para um de seus temas fundamentais: a "utilidade". De acordo com a ciência econômica, os indivíduos decidem no sentido de maximizar sua utilidade, ou seja, de alcançar a maior satisfação possível. Tendo em vista que medir a satisfação sempre foi algo muito difícil, a teoria econômica geralmente parte da ideia de que as "escolhas reveladas" - entre duas mercadorias ou serviços, por exemplo - seriam a única forma de analisar a "utilidade" ou satisfação dos indivíduos, que seria o motivo principal das escolhas que observamos. Em contraposição, há um grupo de economistas que acredita que a "utilidade" deveria ter um conteúdo e que esse conteúdo pode se expressar em termos de felicidade. Em outras palavras, a felicidade seria o objetivo final das escolhas individuais e deveria, portanto, ser estudada em sua plenitude (Frey e Stutzer, 2002). Neste sentido, há um pequeno grupo de sociólogos, psicólogos e economistas que tem se dedicado intensamente ao estudo da felicidade não apenas com o objetivo de descrever o grau de satisfação das populações, mas também de avançar as teorias sobre decisões racionais e motivações nas ciências sociais (Elster, 1998).

O propósito do presente artigo não é discutir essas teorias mais gerais sobre incerteza nas decisões dos indivíduos, mas é importante mencionar que tal problemática está relacionada ao estudo empírico da felicidade. Meu objetivo é analisar empiricamente os principais fatores rela- 
cionados ao grau de felicidade da população brasileira. Em outras palavras, busca-se aqui verificar quais fatores aumentam e quais diminuem as probabilidades dos indivíduos se declararem felizes. Meu principal argumento é que fatores relacionais, e não apenas individuais, são fundamentais. Além de fatores materiais, como renda e educação, normalmente enfatizados nos estudos de economistas, diversos fatores relacionais, como redes de amizade e percepções sobre sua posição na comunidade, são determinantes fundamentais da felicidade. Alternativamente, é possível dizer que estes fatores materiais e relacionais (ou contextuais) são fundamentais para descrever os determinantes da desigualdade de felicidade no Brasil contemporâneo, ou seja, a distribuição desigual não apenas da renda, mas também dos fatores contextuais ou relacionais, leva a uma distribuição desigual da felicidade.

\section{O BRASIL NO CONTEXTO INTERNACIONAL}

Quando observamos o Brasil em perspectiva comparada constatamos imediatamente que nossa população realmente está entre as mais felizes do mundo. Medida em uma escala que vai de 1 a 10 pontos, a média de felicidade entre os brasileiros em 2008 era de 7,5. Segundo os dados compilados pelo sociólogo holandês Veenhoven (1993; 2013), conhecido como o arquivista da felicidade, o Brasil é o $18^{\circ}$ país mais feliz entre os 135 para os quais há informações semelhantes. O povo brasileiro está no topo da distribuição mundial de felicidade, ou seja, entre os 15\% mais felizes. Outros países da América Latina também estão no topo (por exemplo, Venezuela, Costa Rica, Panamá e México), assim como diversos países muito mais desenvolvidos economicamente do que o Brasil (Nova Zelândia, Suíça, Dinamarca e Canadá). De fato, a relação entre desenvolvimento econômico, mensurado pelo Produto Interno Bruto per capita, e o grau de felicidade, medido pela escala de 10 pontos, não é linear. O grau de felicidade aumenta com o PIB per capita até certo ponto, mas, depois de um determinado nível de riqueza, PIB per capita em torno de 8.000 dólares, o grau de felicidade das populações tende a não aumentar mais (Easterlin, 2002; Lane, 2000).

Estes dados levaram diversos autores (Easterlin, 2002; Lane, 2000) a afirmar que o "bem-estar subjetivo" aumenta na medida em que as populações deixam de ser pobres, mas não continua aumentando com o crescimento da riqueza nos países que já possuem a maior parte de sua população gozando de condições materiais ou econômicas relativamente elevadas. Em linguagem mais popular poderíamos dizer que o

DADOS - Revista de Ciências Sociais, Rio de Janeiro, vol. 58, nº 1, 2015 
dinheiro compra a felicidade até um determinado ponto de riqueza, a partir do qual passa a não ser mais tão importante. Além disso, há pesquisas nessa área discutindo os efeitos relativos e de satisfação com a renda como fatores importantes determinando a felicidade (Clark e Oswald, 1996; Veenhoven, 1991). A felicidade dependeria mais da avaliação que as pessoas fazem sobre sua posição na distribuição de renda do que da renda que realmente recebem.

Outra questão relevante, quando pensamos em termos globais de uma nação, é verificar o grau de desigualdade de felicidade. A média pode ser alta, como observamos para o Brasil, mas a dispersão em torno da média (medida pela variância) também pode ser elevada, o que indicaria alta desigualdade de felicidade. Em termos de desigualdade, o Brasil se encontra mais ou menos no meio da distribuição dos 135 países mencionados, ou seja, é o 470 país onde há mais desigualdade de felicidade. A relação entre média (nível geral) e desvio padrão (desigualdade) de felicidade em 135 países pode ser observada no Gráfico 1. Os dados indicam que há uma relação linear positiva entre média e desvio padrão de felicidade. Quanto maior a média, menor a desigualdade. No gráfico, o Brasil aparece na parte superior vertical, média alta de felicidade, e no meio do eixo horizontal, desigualdade intermediária.

De fato, o Gráfico 1 permite observar a posição do Brasil em relação a outros países. Por exemplo, o grau geral de felicidade é muito mais baixo em Togo do que no Brasil, mas o grau de desigualdade não é tão maior assim. O país mais feliz de todos é a Costa Rica (média 8,5), mas o com maior média e menor desigualdade de felicidade é a Holanda. Em um outro extremo, Angola é muito desigual (desvio padrão de 3,3 ) e tem uma média de felicidade intermediária $(4,6)$. Embora o grau de felicidade seja semelhante entre o Brasil e a Holanda $(7,5$ e 7,6), a desigualdade é muito maior entre os brasileiros do que entre os holandeses.

Estas informações são bastante conhecidas e já foram apresentadas em diversos outros trabalhos fazendo comparações internacionais sobre o grau de "bem-estar subjetivo" no mundo (Diener, 2009; Diener, Diener e Diener, 1995; Diener e Suh, 2000; Graham, 2011; Graham e Pettinato, 2002; Helliwell, Layard e Sachs, 2012; Inglehart, 1990; Kahneman, Diener e Schwarz, 1999; Deaton, 2013). Meu propósito neste artigo é mensurar mais detalhadamente os determinantes da desigualdade de felicidade no Brasil, utilizando os dados mais recentes disponíveis. 
Gráfico 1

Média por Desvio Padrão de Felicidade (Bem-Estar Subjetivo)

em 135 Países do Mundo

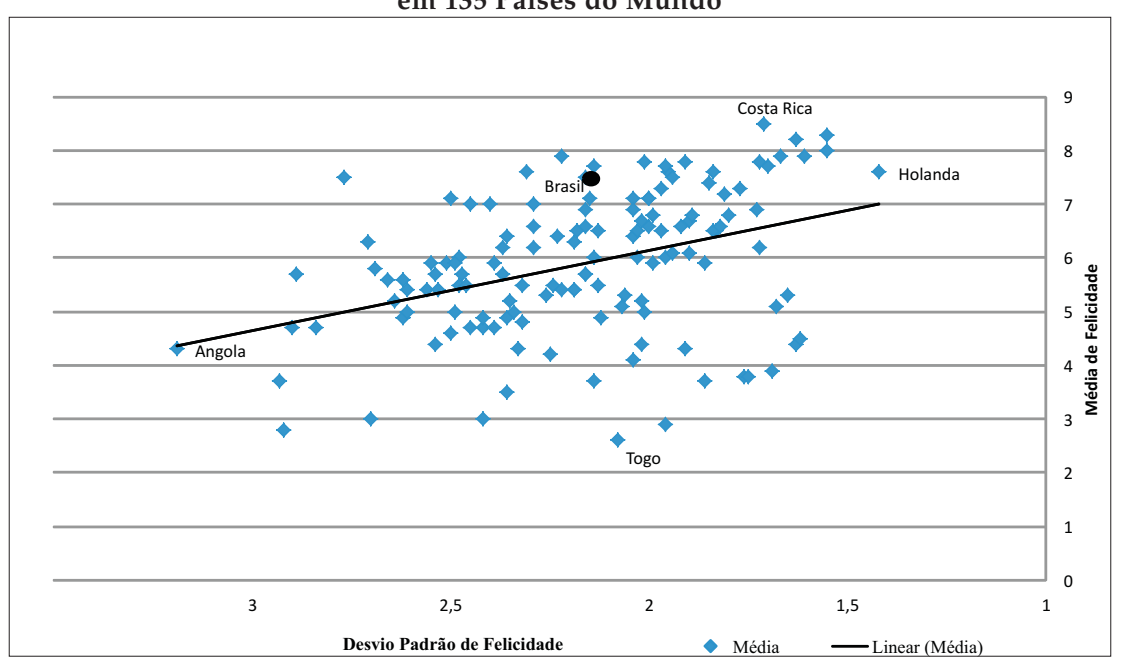

Fonte: Veenhoven (2014)

\section{DADOS, VARIÁVEIS E MÉTODOS}

Neste artigo uso dados da "Pesquisa Dimensões Sociais das Desigualdades" (PDSD daqui em diante). A PDSD é uma amostra representativa da população brasileira urbana e rural, com exceção da área rural da região Norte, que inclui apenas 3,3\% da população do país. Coletada entre outubro e novembro de 2008, a PDSD é composta por uma amostra de 8.048 domicílios nos quais foram entrevistados chefes e cônjuges (caso houvesse) e coletadas informações básicas sobre todos os moradores. A amostra é inteiramente probabilística e estratificada em múltiplos estágios, o que permite inferências acuradas dos parâmetros populacionais. A seleção dos casos seguiu um procedimento probabilístico em três etapas. Na primeira, foram selecionados os municípios; na segunda, os setores censitários dentro dos municípios; e na terceira, os domicílios dentro dos setores. Um grande conjunto de questões, incluindo duas perguntas-padrão sobre felicidade, foi apresentado para chefe e cônjuge em cada domicílio. Para os chefes há um conjunto ainda maior de perguntas sobre percepção em relação à renda e ao "capital social", entre outras.

Tendo em vista que algumas perguntas sobre percepção e opinião só foram feitas para o chefe do domicílio (categoria majoritariamente 
atribuída pelos entrevistados aos homens), selecionei duas amostras separadas por sexo. Uma para homens e outra para mulheres, ambas para indivíduos com 25 anos ou mais de idade. A amostra dos homens inclui 4.158 indivíduos e é usada para estimar a variação na média de felicidade de acordo com diversas características, incluindo percepção sobre renda e "capital social". A segunda amostra inclui 4.793 mulheres, mas não pode ser utilizada para analisar os efeitos de satisfação com a renda e de capital social na felicidade porque estas variáveis não estão disponíveis para a maioria das mulheres que responderam ao questionário na condição de cônjuges e não de chefes. De acordo com Inglehart (1990) as mulheres tendem a ser ligeiramente mais felizes do que os homens; o Brasil segue esse padrão, de acordo com os dados analisados neste artigo. A análise separada para homens e mulheres também é relevante porque algumas variáveis independentes, que apresento a seguir, têm efeitos distintos para cada sexo.

\section{Variáveis}

A felicidade, que é a variável dependente neste artigo, é mensurada a partir das seguintes perguntas:

(1) Agora vamos falar um pouco da sua vida hoje. Pensando numa escala de 1 a 10, onde 1 representa "levo hoje a pior vida possivel" e 10 representa "levo hoje a melhor vida possível", que nota você daria para a sua vida hoje em dia?

Esta pergunta é normalmente feita em pesquisas sobre felicidade. As médias e desvios-padrão de felicidade comparadas entre 135 países na seção anterior deste artigo foram todas obtidas por perguntas semelhantes a essa. Na PDSD de 2008 também foi feita uma outra pergunta canônica:

(2) Agora, levando em conta os diversos aspectos da sua vida, você diria que está: 1( ) Extremamente feliz; 2( ) Muito feliz; 3( ) Um pouco feliz; 4( ) Nem feliz nem infeliz; 5( ) Um pouco infeliz; 6( ) Muito infeliz; ou 7( ) Extremamente infeliz.

Muitos investigadores e leitores podem duvidar da validade destas perguntas para mensurar a felicidade. A primeira dúvida, legítima, que se levanta diz respeito ao fato de o conceito de felicidade ser muito amplo e não poder ser mensurado usando questões tão simples como estas. De fato, falar em felicidade talvez seja um pouco exagerado, por 
isso alguns autores preferem o termo "bem-estar subjetivo", mas mesmo assim seria válido imaginar que tal ideia não pode ser mensurada tão facilmente. Mudanças de humor, até mesmo relacionadas ao tamanho dos questionários, poderiam influenciar as respostas a perguntas tão subjetivas. Felizmente, vários pesquisadores, principalmente na área de psicologia, fizeram testes e experimentos comparando essas perguntas com uma série muito mais ampla de perguntas sobre o "bem-estar subjetivo". O psicólogo, e também vencedor do Nobel em economia, Daniel Kahneman (Kahneman, Diener e Schwarz, 1999; Kahneman e Krueger, 2006), por exemplo, mostra que perguntas simples estão fortemente correlacionadas à mensuração objetiva da felicidade observada em pesquisas medindo diretamente aspectos físicos da satisfação ou detalhes sobre a satisfação em diversos momentos do dia (usando pesquisas de uso do tempo e outros métodos semelhantes). Kahneman e outros autores (Kahneman, Diener e Schwarz, 1999) argumentam que a avaliação do "bem-estar subjetivo" a partir de perguntas simples e globais sobre a satisfação com a vida retratam de forma relativamente acurada a felicidade ${ }^{5}$. Este tipo de análise desenvolvida na área de psicologia contribui para validar as perguntas sobre felicidade que vinham sendo coletadas há muito tempo em pesquisas de opinião conduzidas por sociólogos e cientistas políticos.

De acordo com essa perspectiva, é aceitável inferir o grau geral de felicidade da população a partir de perguntas gerais (como as $1 \mathrm{e} 2$ ). A inspeção dos Gráficos 2 e 3 a seguir permite, portanto, concluir que a maioria dos brasileiros se sente satisfeito com a vida, ou razoavelmente feliz. De fato, para a primeira pergunta sabemos que $83,8 \%$ dos brasileiros atribuíram nota 5 ou mais para a satisfação com as suas vidas; $20 \%$ afirmaram levar "a melhor vida possível". Para a segunda pergunta, 85\% afirmaram estar: "um pouco feliz", 26,9\%; "muito feliz", 49,7\%; ou "extremamente feliz", 8,5\%. Realmente, o povo brasileiro parece ser predominantemente feliz, como sugere a autoimagem de país alegre.

No entanto, como mencionei na seção anterior, a felicidade não está igualmente distribuída entre todos os brasileiros, ou seja, alguns são mais felizes do que outros. Há desigualdades na distribuição de felicidade. O principal objetivo deste artigo é investigar quais fatores estão correlacionados à felicidade e, por assim dizer, determinam o grau de desigualdade de felicidade. Em outras palavras, podemos dizer que as distribuições dos Gráficos 2 e 3 não levam em conta diferenças impor-

DADOS - Revista de Ciências Sociais, Rio de Janeiro, vol. 58, nº 1, 2015 


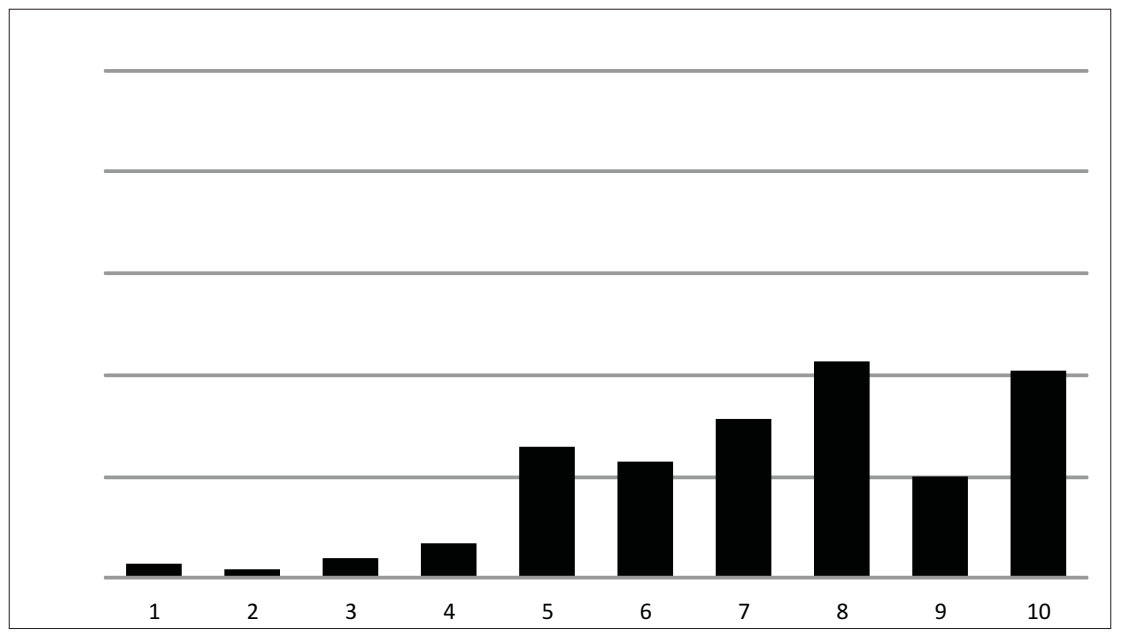

Fonte: PDSD (2008).

tantes entre os indivíduos. Será que as pessoas com renda mais alta se sentem mais satisfeitas com a vida do que as com renda mais baixa? Será que as pessoas que avaliam positivamente sua saúde se sentem mais felizes do que as que a avaliam negativamente? Será que as pessoas que contam mais com os amigos são mais satisfeitas com a vida do que as que contam menos? Os casados tendem a ser mais felizes do que os solteiros? Como estas e outras características se combinam e se relacionam ao grau de felicidade passível de mensuração?

Para responder a estas perguntas estimei diversos modelos de regressão linear, regressão logística ordenada e regressão probit ordenada. Todos os modelos levam a conclusões muito semelhantes, de forma que, na próxima seção, apresento os resultados do modelo de regressão logística ordenada por serem de mais fácil interpretação. Vale lembrar que estimei modelos ora usando a pergunta 1 , ora a 2 como variáveis dependentes. Como esperado, os resultados também são muito semelhantes, já que as respostas a ambas as perguntas estão altamente correlacionadas ${ }^{6}$. Portanto, apresentarei na próxima seção os resultados do modelo logit ordenado usado para estimar os efeitos de diversas variáveis independentes na felicidade, que é medida pela pergunta 1 (escala de 10 pontos). Antes de mostrar o resultado, apresento quais foram as variáveis independentes utilizadas. 
Gráfico 3

Respostas à Pergunta 2, Homens e Mulheres

(Brasil)

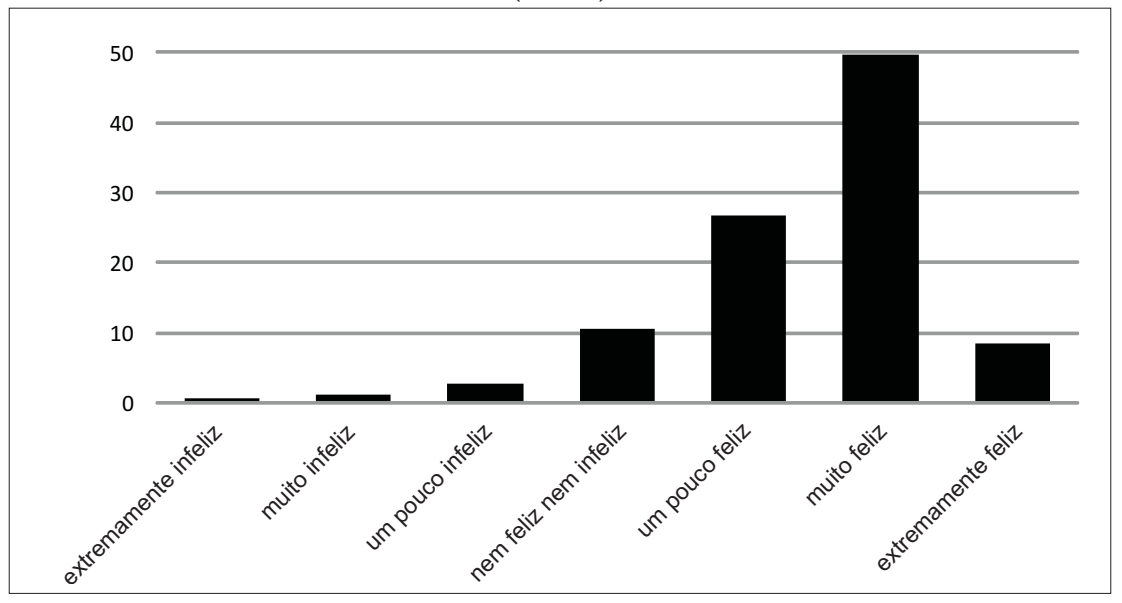

Fonte: PDSD (2008)

Usei algumas variáveis medindo características demográficas e objetivas dos indivíduos e outras medindo relações sociais e percepções em relação a aspectos da vida. Para escolher as variáveis recorri à literatura sobre felicidade que já definiu algumas que são importantes em diversos países e épocas. A primeira característica que usei para explicar a variação na felicidade foi a renda. De acordo com alguns autores (Blanchflower e Oswald, 2000; Duncan, 1975; Furnham e Argyle, 1998), a satisfação com a vida aumenta significativamente com a renda até um certo ponto, a partir do qual passa a ser menos importante, ou seja, o efeito da renda é inicialmente linear, mas depois tende a diminuir. Por este motivo, incluí a renda usando uma formulação quadrática. Como mostro a seguir, essa variável permanece importante, mas o termo quadrático não se aplica ao modelo estimado para as mulheres. Como a renda tem significados diferentes nas regiões urbanas e rurais, controlei também pelo local de residência.

Outra característica importante é a educação. As pesquisas indicam que pessoas com mais escolaridade, principalmente com nível superior, tendem a estar mais satisfeitas com a vida. É difícil interpretar a correlação entre felicidade e educação. Por um lado, a educação pode estar relacionada às condições socioeconômicas, como a renda, por exemplo. Por outro, alguns autores afirmam que pessoas com mais educação tendem a ter níveis mais altos de aspiração, característica 
que estaria correlacionada à felicidade quando os objetivos aspirados são alcançados (Kahneman, Diener e Schwarz, 1999). Portanto, a principal sugestão da literatura é a de que a relação entre educação e felicidade é indireta. De fato, nas análises feitas para este artigo observei que apenas a educação universitária está correlacionada à felicidade dos homens, mas não à das mulheres.

Além de variar com a renda e a educação, a felicidade varia com a percepção subjetiva das pessoas sobre sua renda, ou seja, pessoas satisfeitas com a renda que recebem também tendem a estar mais satisfeitas com a vida, independentemente do fato de a renda real ser alta, média ou baixa. Portanto, utilizo uma pergunta sobre a satisfação com a própria renda para mensurar este aspecto subjetivo da renda. Enquanto a mensuração da renda indica em que posição da distribuição de renda os indivíduos se encontram, a satisfação com a renda está correlacionada à percepção que os indivíduos têm de sua renda em relação às pessoas que estão à sua volta. Alguns autores afirmam que esse segundo aspecto da renda, o que chamam de "renda relativa", seria mais importante do que a renda propriamente dita para explicar o grau de felicidade (Easterlin, 1995). Os indivíduos tendem a considerar sua renda ruim ou boa fazendo comparações subjetivas entre o que recebem e o que os outros à sua volta recebem em termos financeiros. Em outras palavras, a satisfação com a renda depende do contexto e está relacionada ao conceito de "renda relativa". Mesmo pessoas com rendas baixas podem estar satisfeitas com o que ganham, tendo em vista que os outros à sua volta parecem ter rendas menores ou que a renda que possuem em um determinado momento é melhor do que a que possuíam antes.

Outro aspecto relacional importante é a percepção sobre a própria saúde. Várias pesquisas mostram que os indivíduos tendem a considerar a saúde como um dos aspectos mais importantes de suas vidas. Saúde e felicidade estão altamente correlacionadas, mas esse efeito só é observado para a saúde declarada ou percebida. Isso se deve, em parte, ao fato de a saúde e a felicidade declaradas estarem ambas relacionadas à personalidade e às relações sociais. Pessoas mais otimistas e menos neuróticas, por exemplo, tendem a declarar tanto mais satisfação com a vida quanto melhor o estado de saúde (Larsen, 1992), principalmente porque se sentem bem integradas às comunidades em que vivem. Em comparação, a relação entre felicidade e saúde de fato não é tão forte e evidente. Brickman, Coates e Janoff-Bulman (1978) mostram, por exemplo, que pessoas que sofreram graves acidentes não são mais in- 
felizes do que aquelas que nunca sofreram acidentes. As pessoas têm grande capacidade de se adaptar a novas situações que, inicialmente, são de grande penúria como, por exemplo, perda de entes queridos, deficiências físicas etc.

Um fator tão ou mais importante do que a saúde percebida ou declarada são as relações de amizade e afetivas que as pessoas estabelecem. Estas relações estão ainda mais diretamente ligadas à integração dos indivíduos em suas comunidades do que às percepções sobre renda $\mathrm{e}$ saúde. Pessoas que estabelecem relações duradouras de amizade, casamento ou outras tendem a declarar níveis muito mais elevados de felicidade do que pessoas solitárias. Argumento neste artigo que a amizade e o companheirismo são os principais fatores correlacionados à felicidade. Casamento e família representam certamente as relações interpessoais mais importantes na vida dos indivíduos. De fato, um grande número de estudos para diferentes países e períodos revela que o casamento aumenta a felicidade (Diener et al., 2000). A relação entre casamento e felicidade, no entanto, não apresenta uma direção clara, ou seja, será que é o casamento que leva a mais felicidade ou viceversa? Neste sentido, um efeito de seleção não pode ser descartado, a correlação deve ser avaliada com cuidado. No entanto, uma pesquisa cuidadosa feita por Mastekaasa (1995) sugere fortemente que é o casamento que aumenta a felicidade e não o inverso.

Além do casamento, as amizades aumentam a felicidade. De novo o efeito de seleção poderia se aplicar, uma vez que pessoas mais felizes podem ter mais facilidade para encontrar amigos. De qualquer forma, me arrisco a estimar o efeito do "capital social" proporcionado por amigos na felicidade dos indivíduos. Capital social é um conceito inicialmente elaborado pelo economista Glenn Loury (1977) e posteriormente desenvolvido por alguns sociólogos (Bourdieu, 1986, 1989; Coleman, 1988) para descrever a rede de relações (de amizade e outras) às quais os indivíduos pertencem e que podem ser usadas como um benefício em diversas situações sociais (econômicas, sociais, culturais e pessoais). Para medir a ideia de capital social proveniente dos amigos, elaborei um índice latente que combina informações coletadas em seis perguntas da $\mathrm{PDSD}^{7}$. Todas visavam saber se os respondentes podiam contar com (1) amigos ou colegas de trabalho; ou (2) com conhecidos ou vizinhos, para: (a) ajudar em tarefas de casa, carregar coisas, tomar conta dos filhos; (b) emprestar dinheiro; e (c) fazer companhia ou dar consolo num momento difícil. As respostas foram codificadas dicoto-

DADOS - Revista de Ciências Sociais, Rio de Janeiro, vol. 58, nº 1, 2015 
micamente como sim ou não. A partir do padrão de respostas elaborei um índice latente que combina informações obtidas por estas perguntas - tal índice é semelhante a um índice de bens proposto em pesquisas anteriores (Filmer e Pritchett, 1999; Sahn e Stifel, 2003).

Elaborei este índice usando análise de componentes principais, uma técnica de redução dos dados que diminui a dimensionalidade do banco de dados capturando a variação que é comum a todas as variáveis originais (McKenzie, 2005). Na prática, esta técnica corresponde a encontrar uma combinação linear de pesos que dê conta da maior parte da variação na matriz de variância e covariância. O índice de "capital social" é baseado na combinação das variáveis antes descritas. Quanto maior o valor do índice, maiores as chances das pessoas poderem contar com a ajuda de amigos, colegas de trabalho ou vizinhos. Interpreto o índice como sendo uma medida da rede de relações dos indivíduos, quanto maior o valor do índice, mais intensa seria a rede de relações e, neste sentido, o "capital social". De fato, como veremos, há uma relação positiva e extremamente importante entre capital social e felicidade, como sugere a literatura sobre felicidade (Kahneman, Diener e Schwarz, 1999).

Outro aspecto intimamente ligado às relações sociais é a religiosidade. Segundo Ellison (1991), o envolvimento com atividades religiosas está positivamente correlacionado à felicidade. A religião ofereceria uma "chave interpretativa" que pode ajudar a dar sentido à vida. Uma interpretação diferente é a de que pessoas religiosas que frequentam muito os cultos tendem a ser mais felizes e os que frequentam pouco ou não participam tendem a ser menos felizes. Os ateus, por sua vez, não sentiriam culpa por não frequentar cultos e seriam tão felizes quanto os mais crentes devotos. De qualquer forma, a literatura indica que a religião está correlacionada, mas não fortemente, à felicidade. A religiosidade também é uma característica relacional que captura a integração dos indivíduos nas comunidades a que pertencem. Neste sentido, a religiosidade também depende em grande medida de relações sociais e poderia ser concebida como um bem relacional, em contraposição aos bens materiais (como a renda).

Finalmente, é importante controlar pelo efeito da idade. No senso comum, a ideia de felicidade está correlacionada à juventude. De acordo com essa visão, o envelhecimento levaria à diminuição da satisfação com a vida e os jovens teriam vidas mais animadas e alegres do que os 
mais velhos. As pesquisas sobre o tema contrariam essa ideia de senso comum indicando que as pessoas mais velhas tendem a ser mais felizes do que as mais jovens. Talvez porque tenham alcançado vários de seus objetivos ou estejam mais conformadas por não terem realizado sonhos da juventude. A ansiedade para realizar projetos pode levar a uma diminuição da satisfação com a vida. Além disso, as pessoas mais velhas tendem a ter mais tempo para se dedicar às atividades de lazer e ócio criativo que parecem ser fundamentais para definir a felicidade (Ramírez, 2012). No entanto, assim como ocorre com a educação, a correlação entre idade e felicidade também não é de fácil interpretação. De fato, os estudos chegam a conclusões distintas, alguns mostram que a felicidade aumenta com a idade, outros mostram que diminui. Algumas pesquisas (Diener e Suh, 1997; Horley e Lavery, 1995; Oswald, 1997) indicam que a relação entre idade e felicidade tem a forma de $U$, ou seja, diminui até meados da vida, e aumenta com o envelhecimento. Estes autores chegaram a essa conclusão a partir de um estudo controlado por diversas características, inclusive saúde, e compararam dados para os EUA e a Inglaterra. De qualquer forma, é fundamental controlar o efeito das outras variáveis por idade e educação que teriam impactos indiretos na felicidade.

Enfim, para explicar a variação na felicidade, medida pela pergunta 1, utilizo, por um lado, variáveis medindo condições materiais dos indivíduos: (1) renda e renda ao quadrado; (2) educação (educação universitária, ou menos); (3) residência (urbana ou rural); e, por outro lado, variáveis medindo relações e percepções sociais (características relacionais): (4) percepção sobre a renda (muito satisfeito, satisfeito, insatisfeito ou muito insatisfeito); (5) percepção sobre a própria saúde (excelente, muito boa, boa, razoável ou ruim); (6) estado civil (casado, morando junto, separado, viúvo ou solteiro); (7) capital social (índice contínuo variando de menos para mais tal como descrito anteriormente); e (8) religiosidade (frequenta culto mais de uma vez por mês, menos de uma vez por mês, religioso que não frequenta culto e ateu $)^{8}$. O principal objetivo é mostrar que, além das condições materiais, as percepções e relações sociais são fundamentais para explicar a variação de felicidade na sociedade brasileira contemporânea.

\section{Métodos e Modelos}

Estimei diversos modelos (regressão linear, probit ordenado e logit ordenado) para analisar o efeito das variáveis independentes aqui des- 
critas nas variáveis obtidas pelas perguntas 1 e 2, também apresentadas. Os resultados são muito semelhantes. Por isso desenvolvi mais detalhadamente as análises para o modelo logit ordenado que inclui todas as variáveis independentes (as oito descritas no parágrafo anterior), que é o modelo completo que proponho para esta análise - os modelos para mulheres não incluem as variáveis capital social e percepção sobre a renda porque estas só foram obtidas para os homens. Para chegar a esse resultado final, parti de um modelo nulo contendo apenas o intercepto e fui incluindo as variáveis independentes uma por uma, em modelos subsequentes.

Em um primeiro bloco da análise incluí apenas as variáveis relacionadas às condições materiais (renda, área de residência e educação) mais a idade e o estado civil. Este modelo se ajustou bem aos dados e, de certa forma, reproduz resultados encontrados anteriormente para o Brasil (por exemplo, Corbi e Menezes-Filho, 2006). É um modelo que inclui basicamente variáveis medindo as condições materiais, embora o estado civil indique a presença de relações sociais fortes. Os casados tendem a ser mais felizes no modelo estimado, o que também já havia sido observado anteriormente (por exemplo, Corbi e Menezes-Filho, 2006).

Em um segundo bloco de análise incluí as variáveis medindo diversas formas de relação social, integração na comunidade e percepções, ou seja, as variáveis para percepção sobre a própria saúde, religiosidade, satisfação com a renda e capital social (rede de amizades). O modelo com todas essas variáveis tem um ajuste muito melhor aos dados, ou seja, esse modelo completo - incluindo condições materiais, relações sociais e percepções - leva a uma explicação mais adequeda da distribuição de felicidade na população. Em termos substantivos isso significa que percepções e relações sociais são extremamente importantes para explicar a felicidade da população.

Apesar de o modelo final, que apresento na próxima seção, ser adequado, fiz algumas análises para testar seus pressupostos matemáticos e estatísticos. Tanto para homens quanto para mulheres, a especificação do modelo logit ordenado final $l^{9}$ apresenta um problema: viola o pressuposto das chances proporcionais ou das regressões paralelas. Segundo esse pressuposto, o intercepto da regressão logit ordenada para cada categoria da variável dependente muda, mas a inclinação da reta (o efeito de cada variável independente) não se modifica, apenas aumenta ou diminui proporcionalmente à mudança no intercepto (Long, 
1997). Para avaliar esse pressuposto usei dois testes apresentados por Long (idem): um teste global, chamado "Score Test", e um verificando a quebra do pressuposto para cada variável independente, o teste de Brant. Tanto para os homens quanto para as mulheres, o pressuposto é violado. Para os homens, o teste global apresenta uma estatística qui quadrado de 383,4 com 168 graus de liberdade, e, para as mulheres, uma estatística qui quadrado de 342,7 com 90 graus de liberdade - em ambos os casos isso significa que a hipótese de que o pressuposto foi violado não pode ser rejeitada. O teste de Brant vai além e mostra quais são as variáveis independentes que levam a rejeitar a hipótese das regressões paralelas. Para os homens, elas são: percepção da própria saúde, estado civil, educação, renda, capital social e satisfação com a renda; e, para as mulheres: idade, percepção sobre a própria saúde, renda e educação. Uma alternativa seria excluir todas essas variáveis das análises, mas isso iria empobrecer muito as conclusões.

Outra alternativa diante desta limitação metodológica é utilizar outro tipo de modelo. Usei, então, o modelo logit ordenado generalizado (Williams, 2006) para o qual o pressuposto acima não se aplica. Este modelo pode ser considerado como intermediário entre o logit ordenado e o logit multinomial. O primeiro, mais simples, o segundo, muito mais complexo. Usando as mesmas variáveis independentes estimei um modelo logit ordenado generalizado para os homens e outro para as mulheres. Novamente esbarrei em dificuldades metodológicas. Assim como qualquer modelo estatístico, o logit ordenado generalizado (sintaxe gologit2 no Stata) também deve ser usado com cuidado. No caso do modelo usado o problema é que há a possibilidade de obtenção de probabilidades preditas negativas. O que é uma impossibilidade matemática ${ }^{10}$. Essa limitação pode ser contornada a partir da estimação de modelos intermediários entre o logit ordenado e o logit ordenado generalizado, isso é obtido ao impormos restrições para que algumas variáveis independentes sigam o mencionado pressuposto das chances proporcionais. Ao fazer isso observamos que, para a maioria das variáveis independentes, $80 \%$ delas, o pressuposto não é violado. O uso do modelo logit ordenado generalizado, com restrições, não modifica muito a análise alcançada pelo modelo logit ordenado. Ou seja, os resultados são muito semelhantes e a quebra do pressuposto não leva a conclusões díspares em relação ao modelo logit ordenado. Neste sentido, apresento os resultados para o primeiro modelo não apenas porque não diferem significativamente dos resultados do último modelo, mas sobretudo porque a interpretação é mais direta e simples ${ }^{11}$.

DADOS - Revista de Ciências Sociais, Rio de Janeiro, vol. 58, nº 1, 2015 
Os parâmetros estimados e as estatísticas de ajuste para este modelo final são apresentados na Tabela 1 .

\section{"DETERMINANTES" DA FELICIDADE NA POPULAÇÃO BRASILEIRA}

Em seguida, passo a relatar os efeitos individuais de cada variável independente, controlando-os pelo efeito de todas as outras. No final desta seção apresento a variação de felicidade por renda para dois tipos de indivíduos: os com maiores e menores probabilidades de serem felizes. A Tabela 1 apresenta os coeficientes estimados pelo modelo proposto para descrever a variação na felicidade de brasileiros e brasileiras. De fato, os padrões de associação observados para o Brasil são muito semelhantes àqueles descritos para pesquisas realizadas em diversos países do mundo (Frey e Stutzer, 2002). Em outras palavras, do ponto de vista adotado no presente artigo, os determinantes da felicidade no Brasil não são muito diferentes dos observados em diversas outras nações. Talvez o que diferencie o Brasil seja o grau e a desigualdade na distribuição de felicidade. Além disso, os resultados encontrados para as variáveis renda, educação, estado civil e idade são semelhantes aos encontrados anteriormente para o Brasil (Corbi e Menezes-Filho, 2006). Neste sentido, a principal contribuição das minhas análises é mostrar que as variáveis para percepção sobre renda e saúde, para capital social (rede de amizades) e para religião são fundamentais para explicar a felicidade da população. Assim sendo, não é apenas a renda (as condições materiais) que determina a felicidade da população, outras formas de relação social são ainda mais relevantes do que a renda.

No Brasil, como já sabíamos, a felicidade aumenta com a idade. Levando-se em conta todas as variáveis incluídas nos modelos da Tabela 1, observamos que, para cada ano a mais de idade, a felicidade aumenta $0,74 \%$ para os homens e $0,16 \%$ para as mulheres. Portanto, controlar pelo efeito da idade é bastante relevante para verificar em que medida renda, percepções e relações sociais se associam à felicidade. É importante notar que testei o uso de uma formulação quadrática para idade, o que indicaria que a felicidade varia de forma não linear com a idade. Esse termo é estatisticamente significativo antes de incluir as variáveis para percepção sobre a renda e sobre a saúde, mas torna-se irrelevante depois que estas duas últimas variáveis são incluídas. Portanto, a ideia de que a felicidade diminui e cresce com a idade (uma relação tendo a forma de $\mathrm{U}$ ), anteriormente aventada para o caso brasi- 
Tabela 1

Modelos Logit Ordenados para Nota (1 a 10) Atribuída à Pergunta: "Agora vamos falar um pouco da sua vida hoje, pensando numa escala de 1 a 10 , em que 1 representa 'levo hoje a pior vida possível' e 10 representa 'levo hoje a melhor vida possível'", homens e mulheres, 25 anos ou mais

(Brasil, 2008)

\begin{tabular}{|c|c|c|c|c|c|c|c|c|}
\hline \multirow{2}{*}{ Variáveis Independentes } & \multicolumn{4}{|c|}{ Homens } & \multicolumn{4}{|c|}{ Mulheres } \\
\hline & Coef. & & S.E. & O.R. & Coef. & & S.E. & O.R. \\
\hline Idade $^{\wedge}$ & 0,072 & $* *$ & 0,003 & 1,074 & 0,016 & $* * *$ & 0,003 & 1,016 \\
\hline Saúde: Excelente & 1,215 & $* * *$ & 0,207 & 3,369 & 1,261 & $* * *$ & 0,149 & 3,528 \\
\hline Saúde: Muito boa & 0,889 & $* * *$ & 0,195 & 2,434 & 1,071 & $* * *$ & 0,131 & 2,918 \\
\hline Saúde: Boa & 0,792 & $* * *$ & 0,182 & 2,208 & 0,976 & $* * *$ & 0,129 & 2,653 \\
\hline Saúde: Razoável & 0,437 & $* *$ & 0,184 & 1,548 & 0,648 & $* * *$ & 0,100 & 1,911 \\
\hline \multicolumn{9}{|l|}{ Saúde: Ruim (referência) } \\
\hline Civil: Casado & 0,516 & $* * *$ & 0,145 & 1,676 & 0,456 & $* *$ & 0,100 & 1,577 \\
\hline Civil: Morando junto & 0,405 & * & 0,159 & 1,499 & 0,429 & $* * *$ & 0,124 & 1,535 \\
\hline Civil: Separado & $-0,424$ & & 0,210 & & $-0,135$ & & 0,119 & \\
\hline Civil: Viúvo & 0,045 & & 0,222 & & 0,051 & & 0,121 & \\
\hline \multicolumn{9}{|l|}{ Civil: Solteiro (referência) } \\
\hline Educação: Universidade & 0,178 & * & 0,098 & 1,195 & 0,046 & & 0,083 & \\
\hline \multicolumn{9}{|l|}{ Educação: < Universidade (ref.) } \\
\hline Religiosidade: $<1$ vez mês & $-0,273$ & $* *$ & 0,097 & 0,761 & & & & \\
\hline Religiosidade: não freq. & $-0,168$ & * & 0,088 & 0,845 & $-0,306$ & $* *$ & 0,102 & 0,737 \\
\hline Religiosidade: religioso sem igreja & $-0,204$ & * & 0,131 & 0,815 & $-0,535$ & $* * *$ & 0,141 & 0,586 \\
\hline Religiosidade: Ateu & $-0,435$ & & & & $-0,047$ & & 0,247 & \\
\hline $\begin{array}{l}\text { Religiosidade: + } 1 \text { vez mês (ref. ho- } \\
\text { mens) }\end{array}$ & & & & & - & & & \\
\hline \multicolumn{9}{|l|}{$\begin{array}{l}\text { Religiosidade: Frequenta (ref. mu- - } \\
\text { lheres) }\end{array}$} \\
\hline Renda & 0,056 & $* * *$ & 0,018 & 1,058 & 0,078 & $* * *$ & 0,022 & 1,081 \\
\hline Renda*Renda $\sim$ & $-0,001$ & ** & 0,000 & 0,999 & $-0,001$ & $* *$ & 0,000 & 0,999 \\
\hline Muito satisfeito com a renda & 1,1488 & ** & 0,2239 & 3,154 & - & & & \\
\hline Satisfeito com a renda & 0,3952 & $* * *$ & 0,0688 & 1,485 & - & & & \\
\hline \multicolumn{9}{|l|}{ Insatisfeito com a renda (ref.) } \\
\hline Capital Social (amigos) & 0,3887 & $* * *$ & 0,0689 & 1,475 & - & & & \\
\hline Residência Urbana & $-0,279$ & * & 0,1068 & 0,757 & - & & & \\
\hline
\end{tabular}

(continua)

DADOS - Revista de Ciências Sociais, Rio de Janeiro, vol. 58, nº 1, 2015 
Tabela 1

Modelos Logit Ordenados para Nota (1 a 10) Atribuída à Pergunta: "Agora vamos falar um pouco da sua vida hoje, pensando numa escala de 1 a 10 , em que 1 representa 'levo hoje a pior vida possível' e 10 representa 'levo hoje a melhor vida possível'", homens e mulheres, 25 anos ou mais

(Brasil, 2008) (continuação)

\begin{tabular}{|c|c|c|c|c|c|c|c|c|}
\hline \multirow{2}{*}{ Variáveis Independentes } & \multicolumn{4}{|c|}{ Homens } & \multicolumn{4}{|c|}{ Mulheres } \\
\hline & Coef. & & S.E. & O.R. & Coef. & & S.E. & O.R. \\
\hline \multicolumn{9}{|l|}{ Residência Rural (ref.) } \\
\hline / cut1 & $-3,327$ & $* * *$ & 0,335 & & $-2,237$ & $* * *$ & 0,242 & \\
\hline / cut2 & $-2,754$ & $* * *$ & 0,321 & & $-1,804$ & $* * *$ & 0,230 & \\
\hline / cut3 & $-1,997$ & $* * *$ & 0,299 & & $-1,251$ & $* * *$ & 0,218 & \\
\hline / cut4 & $-1,275$ & $* * *$ & 0,289 & & $-0,670$ & $* * *$ & 0,210 & \\
\hline / cut5 & $-0,057$ & $* * *$ & 0,283 & & 0,462 & $* * *$ & 0,206 & \\
\hline / cut6 & 0,635 & $* * *$ & 0,282 & & 1,037 & $* * *$ & 0,207 & \\
\hline / cut7 & 1,439 & $* * *$ & 0,283 & & 1,702 & $* * *$ & 0,209 & \\
\hline / cut8 & 2,487 & $* * *$ & 0,286 & & 2,636 & $* * *$ & 0,213 & \\
\hline / cut9 & 2,964 & $* * *$ & 0,288 & & 3,212 & $* * *$ & 0,216 & \\
\hline \multicolumn{9}{|l|}{ Estatísticas de ajuste: } \\
\hline Log-Lik Intercept Only: & -8290 & & & & -9580 & & & \\
\hline Log-Lik Full Model: & -8114 & & & & -9428 & & & \\
\hline $\begin{array}{l}\text { LR (19 para homens e } 14 \text { para mu- } \\
\text { lheres): }\end{array}$ & 352,4 & & & & 304,71 & & & \\
\hline $\mathrm{BIC}^{\prime}:$ & $-194,1$ & & & & $-186,1$ & & & \\
\hline $\mathrm{N}$ & 4158 & & & & 4793 & & & \\
\hline
\end{tabular}

Fonte: PDSD (2008).

Obs.: ^ multiplicado por $10 ; \sim$ multiplicado por 1.000 .

*** $\mathrm{p}<0,001 ;{ }^{* *} \mathrm{p}<0,005 ;{ }^{*} \mathrm{p}<0,05$.

leiro (p. ex., Corbi e Menezes-Filho, 2006), não se sustenta quando levamos em conta as percepções sobre renda e saúde.

Em contraste, os modelos estimados comprovam que a felicidade aumenta com a renda mesmo quando se leva em conta todas as variáveis sobre percepção e relações sociais, mas os retornos diminuem a partir de um determinado nível de renda. Uma pergunta de grande interesse e recorrente na literatura é se o dinheiro compra a felicidade. No Brasil, assim como em diversos outros países, a resposta é sim. Deste modo, políticas e tendências de expansão da renda, como as que atualmente 
ocorrem no país, levam ao aumento da satisfação com a vida. De qualquer forma, a renda não é o único nem o mais importante fator de aumento da felicidade.

Os homens com educação universitária também têm chances maiores de estarem satisfeitos com a vida (1,2 vez mais chances) do que os que não alcançaram esse nível educacional. Para as mulheres, esse efeito não é estatisticamente significativo, ou seja, não é possível observar o efeito da educação na felicidade. Tendo em vista que os retornos salariais são extremamente altos para pessoas com educação universitária no Brasil (Ferreira et al., 2006), podemos imaginar que o efeito observado para os homens se relaciona ao fato de que aspirações financeiras e materiais são mais facilmente alcançadas por indivíduos que frequentaram universidades. Assim, é possível dizer que retornos à educação universitária também são observados em termos de felicidade, e não apenas em termos de renda. Homens morando em regiões rurais também tendem a ser mais felizes (1,3 vez mais) do que aqueles que vivem em grandes centros urbanos. A vida no campo aumenta o grau de satisfação com a vida, o que está provavelmente relacionado ao estresse proveniente da vida urbana.

Além destas características relacionadas à vida material que foram anteriormente estudadas no Brasil, as relações sociais influenciam positivamente a satisfação com a vida. Pessoas que estabelecem relações duradouras ou que contam com redes de amigos e conhecidos mais extensas tendem a ser mais felizes. Por exemplo, homens casados aumentam em $67 \%$ e mulheres em $58 \%$ suas chances de serem mais felizes do que, respectivamente, homens e mulheres solteiros. Homens com redes de amizade (capital social) mais amplas também tendem a se sentir mais felizes. Estes aspectos se relacionam ao fato de que a satisfação com a vida depende da relação que as pessoas estabelecem entre si. Aqueles mais conectados com outros geralmente sentem-se mais satisfeitos com a vida de um modo geral. Estas pessoas costumam ter uma atitude mais positiva e otimista em relação a vida.

Este tipo de atitude também se relaciona à percepção sobre a própria saúde e sobre a renda. Segundo a literatura (Frey e Stutzer, 2002), a percepção sobre a saúde é o fator que se relaciona de forma mais forte à felicidade. Pessoas que percebem sua saúde como boa tendem a ser mais felizes. Os hipocondríacos são menos felizes de um modo geral. Para o caso brasileiro encontramos a seguinte relação: homens que conside-

DADOS - Revista de Ciências Sociais, Rio de Janeiro, vol. 58, nº 1, 2015 
ram ter saúde muito boa têm 2,5 vezes mais chances de se sentirem mais satisfeitos com a vida do que homens que consideram ter saúde ruim, para as mulheres a vantagem é de 2,9 vezes mais. Como os modelos que estimei são modelos "logit ordenados", estes efeitos são cumulativos para cada uma das dez categorias (notas) de felicidade obtidas pelas respostas à pergunta 1 .

Outra forma de percepção extremamente importante é a satisfação com a própria renda. Homens que se sentem "muito satisfeitos com sua renda" têm 3 vezes mais chances de serem mais felizes do que aqueles que se sentem "muito insatisfeitos com sua renda". É importante notar que o efeito é observado independentemente da renda real que o indivíduo recebe, ou seja, a satisfação com a renda é tão ou mais importante do que a renda real para determinar o grau de felicidade dos indivíduos. Mais do que isso, a satisfação com a renda é uma medida da "renda relativa", ou seja, é fruto da comparação que os indivíduos fazem da sua renda com a de outras pessoas a sua volta ou com a renda que tinham em um momento anterior. É, portanto, uma característica relacional. O fato de a satisfação com a renda ser relevante para explicar a felicidade indica que as relações sociais (comparações interpessoais) são extremamente importantes. Pessoas que consideram suas rendas satisfatórias, independentemente do valor real da renda, tendem a não se sentir marginalizadas nas comunidades em que vivem. Estão, desse modo, mais integradas em seus grupos sociais. Vale lembrar que não há informação sobre satisfação com a renda para mulheres.

Outro resultado bastante interessante é o relacionado à religiosidade. As análises que desenvolvi indicam que homens e mulheres com religiosidade mais acentuada, que frequentam mais os cultos religiosos, tendem a ser mais felizes do que aqueles que têm religião, mas não frequentam cultos. Em contrapartida, os ateus também tendem a declarar maior satisfação com a vida do que os religiosos que não frequentam cultos. Portanto, não é apenas a religiosidade que aumenta a felicidade, mas também o oposto: a falta de religiosidade. Este resultado é bastante interessante e aponta para o fato de que a ambiguidade nas crenças talvez seja o fator mais importante e não a religiosidade em si. Além disso, esta evidência também indica que o sentimento de pertencimento a uma comunidade é importante, seja ela a comunidade religiosa ou a de não religiosos. Sentir-se à vontade com suas crenças, espelhadas no contato com outros indivíduos que compartilham essa 
crença, parece ser fundamental. Mais uma vez há indícios de que a rede de relações sociais é importante. Até onde vai meu conhecimento, este resultado sobre ateísmo e religiosidade não foi obtido em pesquisas realizadas em outros países. Vale a pena investigar melhor os sentidos dos números e associações obtidos na análise aqui apresentada.

Em suma, os modelos completos que estimei indicam claramente que a felicidade não depende apenas das condições materiais, mas sobretudo das relações sociais em que os indivíduos se encontram. Embora a renda seja importante (o dinheiro "compra" alguma felicidade), ela está longe de ser o único ou o principal fator levando os indivíduos a serem mais felizes. Relações afetivas e de amizade, percepções positivas sobre saúde e renda e religiosidade são aspectos fundamentais para explicar a felicidade dos brasileiros. Todos estes últimos fatores podem ser vistos como "bens relacionais", ou seja, "bens" que não podem ser possuídos somente pelos indivíduos e dependem essencialmente da convivência com outras pessoas. Se os outros deixam de participar das relações, elas deixam de fazer sentido. Ter amigos, relações íntimas (casamento ou um companheiro) e participar de cultos são aspectos da vida que dependem das relações sociais. Portanto, a boa vida e a felicidade dependem essencialmente da participação das pessoas em redes de relações sociais, e não apenas das condições materiais. Esta é justamente a conclusão a que chega Ramírez (2012) em um estudo extremamente interessante sobre a vida boa e a felicidade no Equador.

As descrições anteriores são acuradas e baseadas nos modelos apresentados na Tabela 1, mas todas partem da ideia de que cada efeito ocorre independentemente da variação nos outros. Este tipo de pensamento ainda é muito abstrato, ou seja, é preciso imaginar um mundo irreal com algumas características variando independentemente das outras. Na realidade, o modelo que apresentei é aditivo, ou seja, cada característica incluída (variável independente) tem um efeito que se adiciona ao das outras variáveis. Assim, é possível construir tipos representando pessoas com diferentes combinações de características e verificar quais as probabilidades destes tipos de pessoas serem mais ou menos felizes.

Ao observar o Gráfico 2 é possível ter uma ideia geral sobre a distribuição de felicidade na população brasileira como um todo. Por exemplo, sabemos que $20 \%$ dos pesquisados atribuíram nota 10 (levo hoje a me-

DADOS - Revista de Ciências Sociais, Rio de Janeiro, vol. 58, nº 1, 2015 
lhor vida possível) ao responder a pergunta 1 , mas não sabemos se essa proporção aumenta entre os com renda maior, ou entre os casados, ou entre os que consideram ter saúde muito boa. $\mathrm{O}$ modelo estimado e apresentado na Tabela 1 permite verificar como as proporções variam de acordo com as características dos indivíduos (variáveis independentes). É apenas isso que os modelos nos permitem dizer. Como mencionei, a maneira simples de apresentar essa ideia é a elaboração de tipos específicos de indivíduos com características diferentes. Com base nos coeficientes estimados apresentados na Tabela 1, elaborei dois tipos: os indivíduos com maiores probabilidades de serem felizes e os com menores probabilidades. Apresento estes tipos na Figura 1, onde também mostro como o grau de satisfação com a vida varia para eles de acordo com a renda que têm.

Conforme os dados disponíveis e os modelos estimados, os homens com maior probabilidade de serem felizes são os mais velhos, casados, com educação universitária, mais satisfeitos com sua renda, moradores de regiões rurais, contando com muitos amigos, religiosos que frequentam cultos e percebendo sua saúde como excelente. Os menos felizes são os mais novos, solteiros, sem educação universitária, insatisfeitos com sua renda, moradores de regiões urbanas, com poucos amigos, religiosos que não frequentam cultos e que percebem sua saúde como ruim. Os resultados para as mulheres com maiores probabilidades de ser mais e menos felizes são semelhantes aos dos homens, mas sem incluir as informações para satisfação com a renda e rede de amizades (capital social) - lembrem-se que estas duas últimas variáveis não estão disponíveis no banco de dados utilizado para as mulheres. Quanto maior a renda de cada um destes tipos, maior a probabilidade de responderem que estão mais satisfeitos com suas vidas de um modo geral.

Na Figura 1 apresento as probabilidades esperadas para estes tipos, obtidas através dos modelos da Tabela 1, e as comparo com a probabilidade observada, que não leva em conta as características descritas anteriormente - ou seja, as probabilidades observadas para distribuição simples da pergunta 1 (os Gráficos 3b e 4b, no centro da Figura 1, são simplesmente outra forma de apresentar os dados do Gráfico 2). A diferença entre as proporções dos Gráficos $3 b$ e $4 b$ no centro (que não levam em conta as características) e as dos Gráficos 3a e 4a no topo, e 3c e $4 \mathrm{c}$ na base da Figura 1 mostram a variação nas proporções que se de- 
vem às características que aumentam (Gráficos 3a e 4a) ou diminuem (Gráficos 3c e 4c) a probabilidade de ser feliz.

Por exemplo, o Gráfico 3a da Figura 1 mostra que os homens com as características que favorecem a felicidade (descritas pelo modelo e nos parágrafos anteriores) têm probabilidade de $60 \%(0,6)$ de dar a nota 10 para a pergunta, ou seja, probabilidade de achar que levam a melhor vida possível. Esta probabilidade aumenta com a renda, como pode ser visto no gráfico, $60 \%$ das pessoas que recebem mil reais se sentem mui-

\section{Figura 1}

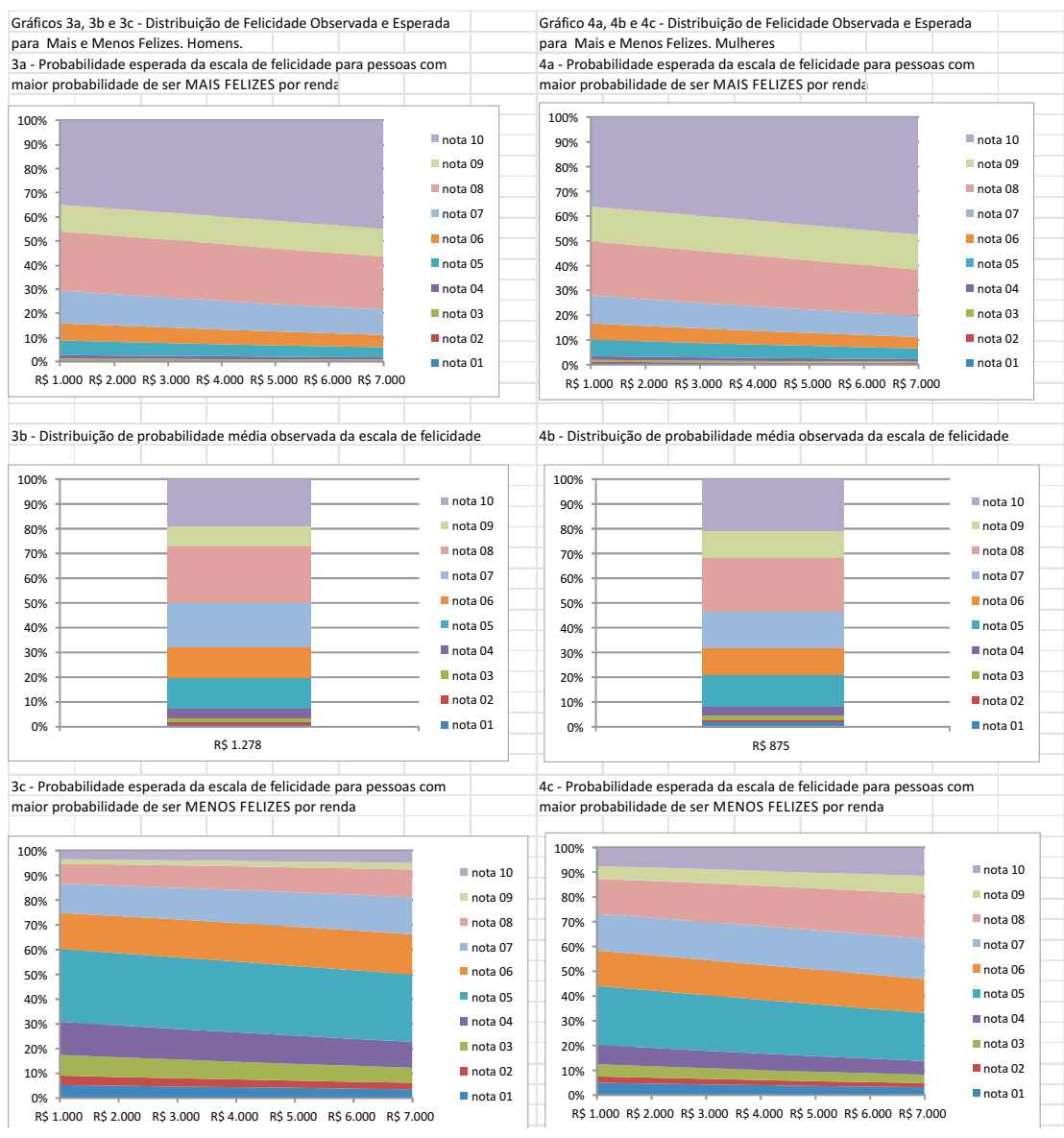

Fonte: PDSD (2008).

DADOS - Revista de Ciências Sociais, Rio de Janeiro, vol. 58, nº 1, 2015 
to satisfeitas, enquanto $70 \%$ das que ganham sete mil reais se sentem muito satisfeitas. Além disso, é fácil observar que a probabilidade para este tipo "mais feliz" é muito mais alta do que a probabilidade quando não se leva em conta as características que aumentam as chances de felicidade (Gráfico 3b). Isso é facilmente observável quando se compara a proporção dando nota 10 no Gráfico $3 \mathrm{~b}$ (cerca de $20 \%$ ) com a proporção dando nota 10 no Gráfico 3 a (cerca de $60 \%$ ) dos mais felizes. No outro extremo, representado no Gráfico $3 c$, temos os homens com as características que diminuem a probabilidade de felicidade. Neste último gráfico a probabilidade de dar nota 10 é de menos de 3\%. Comparações semelhantes podem ser feitas para as mulheres (Gráficos $4 a, 4 b$ e 4c). Sendo assim, é fácil observar nos gráficos da Figura 1 três tipos de pessoas com probabilidades distintas de declarar felicidade.

No topo da Figura 1, Gráfico 3a para homens e 4a para mulheres, temos os tipos com maior propensão para felicidade (mais velhos, casados, com educação universitária, mais satisfeitos com sua renda, moradores de regiões rurais, contando com muitos amigos, religiosos que frequentam cultos e percebendo sua saúde como excelente). Nestes gráficos fica claro que a proporção dando notas mais altas, mais felizes, é muito mais alta, o que significa que as probabilidades de se considerar feliz são maiores para pessoas com tais características. Na base da Figura 1, Gráfico 3c para homens e 4c para mulheres, temos os tipos com menor propensão para felicidade (mais novos, solteiros, sem educação universitária, insatisfeitos com sua renda, moradores de regiões urbanas, com poucos amigos, religiosos que não frequentam cultos e que percebem sua saúde como ruim). Nestes gráficos fica claro que a proporção dando notas mais baixas, menos felizes, é muito mais alta, o que significa que as probabilidades de se considerar infeliz são maiores para pessoas com tais características. Entre os dois extremos estariam as probabilidades de pessoas com combinações distintas de características que facilitam a felicidade.

Obviamente, as análises apresentadas aqui não são determinísticas, mas sim probabilísticas. Ou seja, estamos definindo características que aumentam a probabilidade de as pessoas afirmarem que são mais satisfeitas com as vidas que levam. Há pessoas muito felizes, mas que apresentam todas as características que favoreceriam a insatisfação. $O$ que nossas análises indicam são tendências gerais, há sempre a possibilidade de exceções e casos particulares. Em outras palavras, essas análises podem dar a impressão de que temos uma fórmula para alcan- 
çar a felicidade. Mas essa impressão é obviamente errônea. Ao dizer que as características definidas estão correlacionadas a uma maior satisfação com a vida, não estou querendo dizer que determinam completamente a felicidade. São apenas características que estão correlacionadas a uma maior probabilidade de os indivíduos afirmarem que são felizes. Não há relação causal nem determinística, mas apenas uma associação expressando uma maior tendência ou probabilidade de pessoas com as características descritas considerarem-se satisfeitas com a vida. Muitos outros aspectos da vida e das personalidades das pessoas, que não foram aqui expostos, se relacionam a sua satisfação com a vida. O modelo que estimei apenas descreve como a média de felicidade varia entre indivíduos com tais características. Essa informação é relevante porque possibilita uma melhor descrição da distribuição de felicidade na população brasileira.

\section{CONSIDERAÇÕES FINAIS}

Neste artigo argumentei que a felicidade depende tanto de fatores materiais, como renda e educação, quanto de fatores relacionais, como redes de amizade e relacionamentos íntimos. Também mostrei que percepções positivas sobre renda, saúde e religiosidade são fatores que aumentam a probabilidade de ser feliz. Estudos anteriores sobre o Brasil enfatizaram apenas a relação entre condições materiais e felicidade. Neste sentido, minhas análises avançam em relação às pesquisas anteriores na medida em que mostram que percepções positivas e relações sociais de amizade e companheirismo estão fortemente correlacionadas à felicidade. Em outras palavras, as análises confirmam que mais dinheiro aumenta a felicidade, mas que "bens relacionais", que dependem da relação com outras pessoas, aumentam ainda mais a probabilidade de felicidade.

Na literatura sobre felicidade há um longo debate que procura definir se ela depende mais da renda absoluta ou da relativa. A primeira é o tamanho da renda e a segunda é a comparação que as pessoas fazem entre suas rendas e as de outras pessoas. Minhas análises mostram que ambas são importantes covariáveis da felicidade no Brasil. O mais interessante, no entanto, me parece ser o fato de aspectos relacionais da vida social, como satisfação com a renda e rede de amizades, por exemplo, serem altamente relevantes para explicar as probabilidades de uma pessoa ser feliz. Uma longa tradição de estudos em sociologia diz que a integração dos indivíduos em suas comunidades é fundamental

DADOS - Revista de Ciências Sociais, Rio de Janeiro, vol. 58, nº 1, 2015 
para a coesão social e para o bem-estar das pessoas. No caso da sociologia, não é apenas o bem-estar objetivo, mas sobretudo o sentimento de pertencimento e satisfação que seriam importantes para que as pessoas se sentissem integradas em suas comunidades. Nos trabalhos de Émile Durkheim, por exemplo, a integração dos indivíduos em suas comunidades depende do pertencimento a comunidades religiosas, profissionais ou outras. Haveria uma espécie de sentimento de pertencimento que seria fundamental para que os indivíduos se sentissem integrados e para que a sociedade funcionasse de forma adequada. Embora Durkheim não fale de felicidade no sentido dado pela literatura que mobilizei neste artigo, a ideia de que a integração dos indivíduos em suas comunidades é fundamental para o bem-estar perpassa todo o seu trabalho.

Neste sentido, minhas análises seguem indicando que relações sociais tais como amizade, casamento e religiosidade são fatores centrais aumentando as probabilidades de felicidade dos indivíduos sugerem que a perspectiva sociológica é altamente relevante para entendermos melhor a distribuição de felicidade na sociedade brasileira. Não é apenas a renda, ou qualquer outro fator material, que explica o aumento da probabilidade dos brasileiros serem felizes, mas sobretudo a intensidade de suas relações sociais. Pessoas casadas ou que têm um companheiro, com redes de amizade mais densas (capital social) e que tenham alguma crença bem definida (seja religiosidade ou ateísmo convicto) tendem a se sentir mais felizes, independentemente da renda que tenham. É fato, no entanto, que a renda aumenta essa probabilidade, o que indica que a perspectiva materialista não está totalmente errada.

Além disso, minhas análises indicaram que a satisfação com a própria saúde é um dos principais fatores aumentando as probabilidades de felicidade. Esta satisfação não depende diretamente de relações sociais. É importante notar que a satisfação com a saúde não é a saúde propriamente dita, mas sim como as pessoas se sentem. Pode ser que tenham uma saúde comprometida por alguma doença, mas não sintam as consequências imediatas dessa enfermidade. Nestes casos, a satisfação com a saúde é uma expressão da sensação de bem-estar físico. Esse sentimento é extremamente importante para aumentar a probabilidade de a pessoa se declarar feliz. Segundo alguns autores, este seria o principal fator correlacionado à felicidade (Frey e Stutzer, 2002).

O modelo que estimei parece ser o mais completo usado para estudar a distribuição de felicidade no Brasil. Os estudos anteriores utilizando 
dados para o Brasil inteiro enfatizaram a correlação entre renda e felicidade, enquanto minhas análises procuraram definir diversos outros fatores correlacionados à felicidade. O modelo que uso, no entanto, pressupõe que as variáveis independentes são anteriores à variável dependente (felicidade). Em muitos casos, essa ordem das variáveis poderia ser questionada. Por exemplo, será que é a rede de amizade que torna as pessoas mais felizes? Ou será que as pessoas mais felizes tendem a ter redes de amizade mais extensas? O mesmo raciocínio é válido para diversas outras variáveis incluídas nas análises. Esse problema, conhecido como endogeneidade, não pode ser resolvido estatisticamente, ou seja, depende da apreciação de pesquisas anteriores. Por esse motivo, recorri à literatura para construir o modelo que sugiro. Em outras palavras, só incluí no modelo final variáveis que já haviam sido estudadas em trabalhos sobre felicidade desenvolvidos em outros países. O caso brasileiro não difere muito dos outros países para os quais há estudos sobre felicidade.

Assim, tenho alguns parâmetros para afirmar que minhas análises estão relativamente corretas. De fato, a distribuição de felicidade na sociedade brasileira depende de características que também são importantes em diversas outras sociedades. O Brasil não é muito diferente de outros países no que diz respeito às probabilidades de satisfação com a vida. Ao contrário de diversos outros cientistas sociais que sempre procuram encontrar e descrever a excepcionalidade da sociedade brasileira, minhas análises indicam que há certas regularidades encontradas em diversas outras sociedades que também estão presentes no Brasil. Isso não significa que não haja particularidades na sociedade brasileira. Também em termos da distribuição da felicidade o Brasil é extremamente desigual. Além da desigualdade de renda, existe uma enorme desigualdade na distribuição de bem-estar subjetivo. Sabemos que políticas redistributivas e educacionais são fundamentais para diminuir o primeiro tipo de desigualdade, mas para aumentar a igualdade na distribuição de felicidade é preciso investir não apenas no aumento da renda de todos, mas sobretudo em fatores que facilitem relações sociais mais harmoniosas e bens públicos mais eficientes (como, por exemplo, saúde e lazer). Muitas vezes, a insatisfação da população depende mais de "bens relacionais" do que das condições materiais.

(Recebido para publicação em julho de 2013)

(Reapresentado em outubro de 2014)

(Aprovado para publicação em novembro de 2014)

DADOS - Revista de Ciências Sociais, Rio de Janeiro, vol. 58, nº 1, 2015 
Carlos Antonio Costa Ribeiro

\section{NOTAS}

1. Por exemplo, no livro de Neri (2012) sobre a "nova classe média" no Brasil, implicitamente o aumento do consumo é interpretado como algo que contribui para aumentar a "satisfação com a vida".

2. Para uma contribuição filosófica relativamente recente, ver o livro de Marquard (2007).

3. Dados do Instituto de Pesquisa Econômica Aplicada (IPEA): www.ipea.gov.br

4. Frey e Stutzer (2002), por exemplo, mostram que aspectos institucionais da democracia participativa estariam relacionados positivamente ao "bem-estar subjetivo" dos indivíduos.

5. É interessante notar que, quando medidos de forma mais detalhada, ao longo das atividades cotidianas das pessoas, alguns momentos estão mais correlacionados ao bem-estar subjetivo do que outros. Por exemplo, momentos com amigos e em relações íntimas estão fortemente associados ao bem-estar e momentos perdidos no trânsito ou em engarrafamentos estão ligados ao mal-estar (Kahneman e Krueger, 2006).

6. A PDSD-2008, pesquisa usada neste artigo, permite elaborar um índice de saúde mental. A escala de felicidade e o índice de saúde mental estão negativamente correlacionados.

7. Informações sobre este tipo de índice podem ser encontradas em Lin (2001).

8. Também testei o efeito de ter ou não filhos, mas essa variável não foi estatisticamente significativa.

9. O mesmo seria válido para o modelo probit ordenado. Já o modelo de regressão linear apresenta dificuldades por supor que as distâncias entre as categorias da variável dependente são cardinais.

10. McCullagh e Nelder afirmam: "A utilidade dos modelos de regressão com linhas não paralelas (non-parallel regression models) é limitada em alguma medida pelo fato de que as linhas podem eventualmente interceptar. Dessa forma, valores ajustados negativos não podem ser evitados para alguns valores de $\mathrm{x}$, embora isso talvez ocorra fora da margem observada. Se estas interseções ocorrerem em uma região suficientemente remota do espaço de x, este defeito do modelo não é necessariamente sério" (1989:155; tradução livre).

11. Todos os resultados, assim como o banco de dados, podem ser obtidos diretamente com o autor. 


\section{REFERÊNCIAS BIBLIOGRÁFICAS}

BLANCHFLOWER, Daniel e OSWALD, Andrew J. (2000), “Well-Being over Time in Britain and the USA". NBER Working Paper $n \stackrel{0}{\mathbf{7}}$ 7487, National Bureau of Economic Research, Cambridge, MA.

BOURDIEU, Pierre. (1986), "The Forms of Capital", in J. Richardson (ed.), Handbook of Theory and Research for the Sociology of Education. New York, Greenwood, pp. 241-258.

. (1989), Distinction: A Social Critique of the Judgment of Taste. Cambridge, Harvard University Press.

BRICKMAN, Philip; COATES, Dan e JANOFF-BULMAN, Ronnie. (1978), “Lottery Winners and Accident Victims: Is Happiness Relative?". Journal of Personality and Social Psychology, vol. 36, no 8, pp. 917-927.

CAVALCANTI, Tiago V. de V.; GUIMARÃES, Juliana F. e NOGUEIRA, José R. (2009), “Is Brazil the Land of Happiness? Comparative Study Using a Sample with Economics Students from UFPE and Purdue". Brazilian Review of Econometrics, vol. 29, no 1, pp. 17-35.

CORBI, Raphael B. e MENEZES-FILHO, Naércio A. (2006), “Os Determinantes Empíricos da Felicidade no Brasil". Revista de Economia Política, vol. 26, no 4, pp. 518-536.

CLARK, Andrew E. e OSWALD, Andrew J. (1996), "Satisfaction and Comparison Income". Journal of Public Economics, vol. 61, no 3, pp. 359-381.

COLEMAN, James. (1988), "Social Capital in the Creation of Human Capital". The American Journal of Sociology, vol. 94, Suplemento, pp. S95-S120.

DEATON, Angus. (2013), The Great Escape: Health, Wealth and the Origins of Inequality. Princeton, Princeton University Press.

DIENER, Ed. (2009), Culture and Well-Being. New York, Springer.

; DIENER, Marissa; DIENER, Carol. (1995), "Factors Predicting the Subjective Well-Being of Nations". Journal of Personality and Social Psychology, vol. 69, pp. 851-864.

DIENER, Ed e SUH, Eunkook M. (1997), "Subjective Well-Being and Age: An International Analysis". Annual Review of Gerontology and Geriatrics, vol. 17, pp. 304-324.

DIENER, Ed e SUH, Eunkook M. (eds.). (2000), Culture and Subjective Well-being. Cambridge, MA, MIT Press.

DIENER, Ed et al. (2000), "Similarity of the Relations between Marital Status and Subjective Well-Being across Cultures". Journal of Cross-Cultural Psychology, vol. 31, no 4, pp. 419-436.

DUNCAN, Otis Dudley. (1975), “Does Money Buy Satisfaction?". Social Indicators Research, vol. 2, no 3, pp. 267-274.

EASTERLIN, Richard A. (1973), "Does Money Buy Happiness?". The Public Interest, no 30, pp. 3-10.

. (1995), "Will Raising the Incomes of all Increase the Happiness of All?". Journal of Economic Behavior \& Organization, vol. 27, no 1, pp. 35-47.

DADOS - Revista de Ciências Sociais, Rio de Janeiro, vol. 58, nº 1, 2015 
(ed.). (2002), Happiness in Economics. Cheltenham, UK/Northampton, MA, Edward Elgar.

EASTERLIN, Richard A. et al. (2010), "The Happiness-income Paradox Revisited". Proceedings of the National Academy of Sciences, vol. 107, no 52, pp. 22463-22468.

ELLISON, Christopher G. (1991), "Religious Involvement and Subjective Well-Being". Journal of Health and Social Behavior, vol. 32, no 1, pp. 80-99.

ELSTER, Jon. (1998), "Emotions and Economic Theory". Journal of Economic Literature, vol. 36 , no 1, pp. 47-74.

FERREIRA, Francisco H. G. et al. (2006), “Ascensão e Queda da Desigualdade de Renda no Brasil”. Econômica, vol. 8, no 1, pp. 147-169.

FILMER, Deon e PRITCHETT, Lant. (1999), “The Effect of Household Wealth on Educational Attainment: Evidence from 35 Countries". Population and Development Review, vol. 25, no 1 , pp. 85-120.

FREY, Bruno S. e STUTZER, Alois. (2002), Happiness and Economics: How the Economy and Institutions Affect Well-Being. Princeton, Princeton University Press.

FURNHAM, Adrian e ARGYLE, Michael. (1998), The Psychology of Money. London/ New York, Routledge.

GRAHAM, Carol L. (2011). The Pursuit of Happiness: An Economy of Well-Being. Washington, D.C., Brookings Institution Press.

e PETTINATO, Stefano. (2002), Happiness and Hardship. Opportunity and Insecurity in New Market Economies. Washington, D.C., Brookings Institution Press.

HAGERTY, Michael R. e VEENHOVEN, Ruut. (2003), “Wealth and Happiness Revisited: Growing National Income Does Go with Greater Happiness". Social Indicators Research, vol. 64, no 1, pp. 1-27.

HELLIWELL, John; LAYARD, Richard e SACHS, Jeffrey (eds.). (2012), "World Happiness Report". New York, Earth Institute/Columbia University.

HORLEY, James e LAVERY, John J. (1995), "Subjective Well-Being and Age". Social Indicators Research, vol. 34, no 2, pp. 275-282.

INGLEHART, Ronald. (1990), Culture Shift in Advanced Industrial Society. Princeton, Princeton University Press.

(1997), Modernization and Postmodernization: Cultural, Economic, and Political Change in 43 Societies. Princeton, Princeton University Press.

_et al. (eds.). (2004), Human Beliefs and Values: A Cross-Cultural Sourcebook Based on the 1999-2002 Values Surveys. México, Siglo XXI.

ISLAM, Gazi; WILLS-HERRERA, Eduardo e HAMILTON, Marilyn. (2009), “Objective and Subjective Indicators of Happiness in Brazil: The Mediating Role of Social Class". Journal of Social Psychology, vol. 149, no 2, pp. 267-272.

KAHNEMAN, Daniel; DIENER, Ed e SCHWARZ, Norbert. (1999), Well-being: The Foundations of Hedonic Psychology. New York, Russell Sage Foundation.

KAHNEMAN, Daniel e KRUEGER, Alan B. (2006), “Developments in the Measurement of Subjective Well-Being". Journal of Economic Perspectives, vol. 20, no 1, pp. 3-24. 
KAHNEMAN, Daniel e TVERSKY, Amos. (1979), “Prospect Theory: An Analysis of Decision under Risk". Econometrica, vol. 47, no 2, pp. 263-291.

LANE, Robert Edwards. (2000), The Loss of Happiness in Market Democracies. New Haven, Yale University Press.

LARSEN, Randy. (1992), “Neuroticism and Selective Encoding and Recall of Symptoms: Evidence from a Combined Concurrent-Retrospective Study". Journal of Personality and Social Psychology, vol. 62, no 3, pp. 480-488.

LIN, Nan. (2001), Social Capital: A Theory of Social Structure and Action. Cambridge, Cambridge University Press.

LONG, John Scott. (1997), Regression Models for Categorical and Limited Dependent Variables. Thousand Oaks, CA, Sage.

LOURY, Glenn. (1977), "A Dynamic Theory of Racial Income Differences", in P. A. Wallace e A. L. Mund (eds.), Women, Minorities, and Employment Discrimination. Lexington, MA, Lexington Books.

LUZ, Tatiana C. Borges et al. (2011), "Satisfaction with the Neighborhood Environment and Health in Older Elderly: Cross-sectional Evidence from the Bambuí Cohort Study of Aging". Cadernos de Saúde Pública, vol. 27, suplemento 3, pp. S390-S398.

MARQUARD, Odo. (2007), Felicidad en la Infelicidad: Reflexiones Filosóficas. España, Katz.

MASTEKAASA, Arne. (1995), "Age Variation in the Suicide Rates and Self-Reported Subjective Well-Being of Married and Never Married Persons". Journal of Community and Applied Social Psychology, vol. 5, no 1, pp. 21-39.

MENDES-DA-SILVA, Wesley et al. (2013), "Focusing Illusion in Satisfaction with Life among College Students Living in Brazil". Revista de Administração de Empresas (RAE), vol. 53, no 5, pp. 430-441.

McCULLAGH, Peter e NELDER, John A. (1989). Generalized Linear Models. London, Chapman \& Hall/CRC.

MCKENZIE, David J. (2005), "Measuring Inequality with Asset Indicators". Journal of Population Economics, vol. 18, no 2, pp. 229-260.

NERI, Marcelo. (2012), A Nova Classe Média. O Lado Brilhante da Pirâmide. Rio de Janeiro, Saraiva.

OSWALD, Andrew J. (1997), “Happiness and Economic Performance”. Economic Journal, vol. 107, no 445, pp. 1815-1831.

RAMíREZ, René G. (2012), La Vida (buena) como Riqueza de los Pueblos. Hacia una Socioecología Política del Tiempo. Quito, Editorial IAEN.

RUNCIMAN, Walter G. (1966). Relative Deprivation and Social Justice: A Study of Attitudes to Social Inequality in Twentieth-Century England. London, Routledge \& Kegan Paul.

SAHN, David e STIFEL, David. (2003), "Exploring Alternative Measures of Welfare in the Absence of Expenditure Data". Review of Income and Wealth, vol. 49, no 4, pp. 463-489.

STEVENSON, Betsey e WOLFERS, Justin. (2008), "Economic Growth and Subjective Well-Being: Reassessing the Easterlin Paradox". NBER Working Paper No. 14282 National Bureau of Economic Research, Cambridge, MA.

DADOS - Revista de Ciências Sociais, Rio de Janeiro, vol. 58, nº 1, 2015 


\section{Carlos Antonio Costa Ribeiro}

VEENHOVEN, Ruut. (1991), “Is Happiness Relative?". Social Indicators Research, vol. 24, no 1, pp. 1-34.

. (1993). Happiness in Nations: Subjective Appreciation of Life in 56 Nations, 1946-1992. Rotterdam, Netherlands, Erasmus University of Rotterdam.

. (2013). World Database of Happiness. Disponível em: http:/ / www1.eur.nl/fsw / happiness/. Acesso em: 22/05/2014

(2014), Happiness in Nations. World Database of Happiness, Erasmus University Rotterdam, The Netherlands. Disponível em http://worlddatabaseofhappiness. eur.nl/hapãnat/natãfp.php?mode=1. Acessado em junho/2014.

WILLIAMS, Richard. (2006), “Generalized Ordered Logit/Partial Proportional Odds Models for Ordinal Dependent Variables". The Stata Journal, vol. 6, no 1, pp. 58-82. 
Renda, Relações Sociais e Felicidade no Brasil

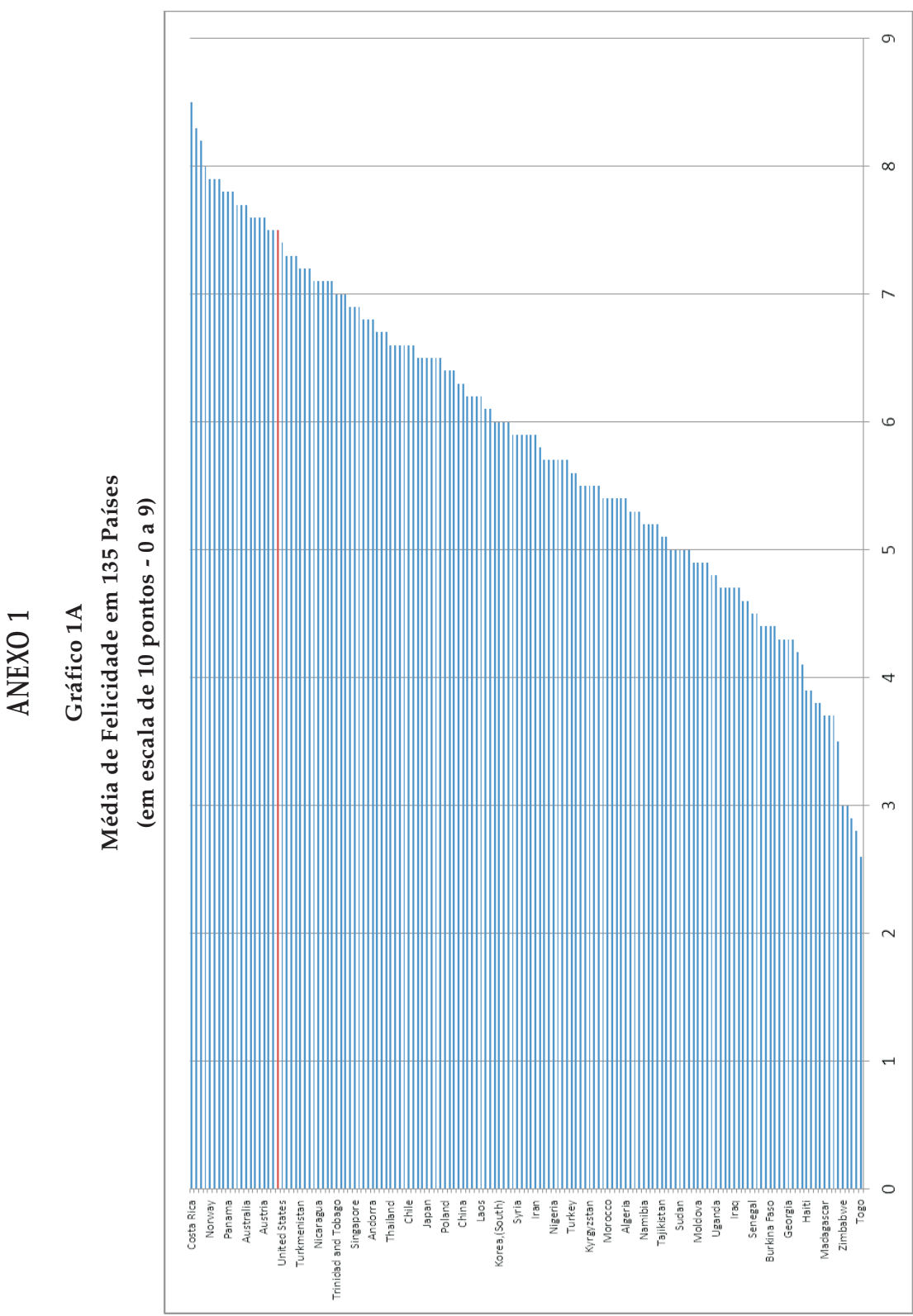




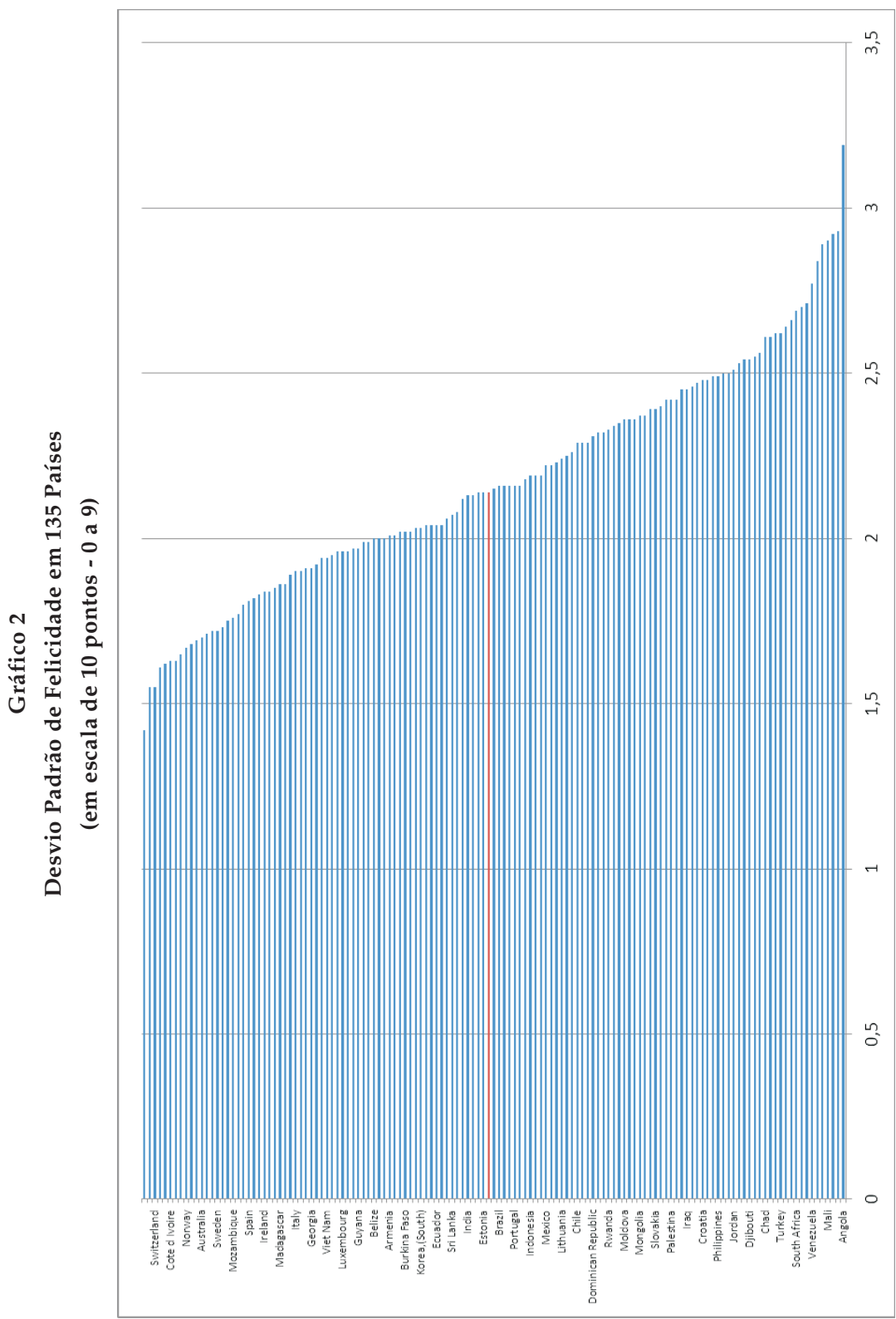


RESUMO

Renda, Relações Sociais e Felicidade no Brasil

O objetivo deste artigo é descrever a distribuição de "bem-estar subjetivo" ou "felicidade" na população brasileira. Após uma breve revisão da literatura em psicologia, economia e sociologia sobre o tema, o texto apresenta dados comparando o Brasil com outros 134 países. O ponto central do artigo consiste na elaboração de um modelo estatístico para descrever os principais fatores correlacionados à "felicidade" da população. Em contraste com trabalhos anteriores sobre o Brasil, nossa análise revela que, além das condições materiais (principalmente a renda), diversas formas de relações sociais e de percepções são fundamentais para explicar a variação na distribuição de "felicidade". Os dados analisados são provenientes da pesquisa "Dimensões Sociais das Desigualdades", composta por uma amostra probabilística da população brasileira coletada junto a 8.048 domicílios em 2008.

Palavras-chave: bem-estar subjetivo; felicidade; renda; estratificação social; relações sociais

\section{ABSTRACT}

Income, Social Relations and Happiness in Brazil

The aim of this article is to describe the distribution of "subjective well-being" or "happiness" among the Brazilian population. In addition to a brief review of the literature in psychology, economy and sociology on the subject, the text presents data comparing Brazil to 134 other countries. The central point of the article is the elaboration of a statistical model capable of describing the main factors correlated to "happiness". In contrast to previous works in Brazil, our analysis reveals that, in addition to material conditions (especially income), several forms of social relation and perception are fundamental to explain the variation in the distribution of "happiness". The data analyzed originates from the research "Social Dimensions of Inequality," composed of a probabilistic sample of the Brazilian population, collected from 8,048 households in 2008.

Keywords: subjective well-being; happiness; income; social stratification; social relationships 
RÉSUMÉ

Revenu, Rapports Sociaux et Bonheur au Brésil

L'objectif de cet article est de décrire la répartition du "bien-être subjectif", ou "bonheur", au sein de la population brésilienne. Après une brève revue de la littérature psychologique, économique et sociologique sur le thème, le texte présentera des données comparatives du Brésil et de 134 autres pays. L'axe central de l'article consiste en l'élaboration d'un modèle statistique pour décrire les principaux facteurs corrélés au "bonheur" de la population. Contrairement aux travaux antérieurs sur le Brésil, notre analyse révèle qu'au-delà des conditions matérielles (principalement liées au revenu), diverses formes de rapports sociaux et de perceptions sont fondamentales pour expliquer les variations constatées dans la répartition du "bonheur". Les données sont issues de la recherche "Dimensions sociales des inégalités" de 2008, basée sur un échantillon probabiliste de la population brésilienne composé de 8.048 foyers.

Mots-clés: bien-être subjectif; bonheur; revenu; stratification sociale; rapports sociaux

\section{RESUMEN}

Renta, Relaciones Sociales y Felicidad en Brasil

El objetivo de este artículo es describir la distribución de "bienestar subjetivo" o "felicidad" en la población brasileña. Tras una breve revisión de la literatura en psicología, economía y sociología sobre el tema, el texto presenta datos comparativos entre Brasil y otros 134 países. El punto central del artículo consiste en la elaboración de un modelo estadístico para describir los principales factores asociados a la "felicidad" de la población. A diferencia de trabajos anteriores sobre Brasil, nuestra análisis revela que, además de las condiciones materiales (especialmente la renta), diversas formas de relaciones sociales y de percepciones son fundamentales para explicar la variación en la distribución de "felicidad". Los datos analizados son provenientes de la investigación "Dimensiones Sociales de las Desigualdades", compuesta por una muestra probabilística de la población brasileña colectada junto a 8.048 domicilios.

Palabras clave: bienestar subjetivo; felicidad; renta; estratificación social; relaciones sociales 